UNIVERSIDADE DE BRASÍLIA

FACULDADE DE EDUCAÇÃO FÍSICA

\title{
EFEITOS SUB-AGUDOS DO EXERCÍCIO COM OCLUSÃO VASCULAR NA FUNÇÃO ENDOTELIAL DE HOMENS JOVENS
}

Flávio Macedo Lahud Paiva 
EFEITOS SUB-AGUDOS DO EXERCÍCIO COM OCLUSÃO VASCULAR NA FUNÇÃO ENDOTELIAL DE HOMENS JOVENS

\author{
FLÁVIO MACEDO LAHUD PAIVA
}

Dissertação apresentada à Faculdade de Educação Física da Universidade de Brasília, como requisito parcial para obtenção do grau de Mestre em Educação Física.

ORIENTADOR: PROF. DR. LAURO CASQUEIRO VIANNA 


\section{AGRADECIMENTOS}

Agradeço primeiramente ao meu orientador Dr. Lauro Casqueiro Vianna, pela paciência, profissionalismo e competência que tornaram possível a realização deste trabalho. Apesar do curto tempo que estive sob sua orientação acredito que o senhor contribuiu de maneira significativa para o meu crescimento acadêmico e pessoal.

Ao professor Dr. Ricardo Moreno Lima, por ter me recebido em seu grupo de estudos ainda durante a graduação e me orientar durante a iniciação científica e o mestrado. A convivência com o senhor durante todos estes anos foi de grande importância para a minha formação.

A todos os membros do Grupo de Estudos em Fisiologia do Exercício e Saúde (GEFS), em especial aos meus colegas de mestrado André Bonadias e Rafael Gauche, o auxilio e companheirismo de vocês foi essencial durante este processo.

Aos membros do Laboratório de Ciências do Exercício (LACE) da Universidade Federal Fluminense, em especial ao professor Dr. Igor Fernandes, por disponibilizarem o laboratório e auxiliarem na coleta de dados.

Aos colegas de pós-graduação que se deslocaram até o Rio de Janeiro para ajudar na coleta de dados: André Bonadias, Mayara Souza, Sílvia Neri e Tácio Rodrigues.

A minha namorada e amiga Isabella Faulhaber Dutra, pelo companheirismo, compreensão e incentivo durante todos estes anos.

A minha família e amigos, pelo incentivo e auxílio em todos os momentos.

A todos os professores e funcionários da Faculdade de Educação Física da Universidade de Brasília, que contribuíram de maneira direta ou indireta para a minha formação.

Ao Centro de Aperfeiçoamento em Pessoal de Ensino Superior (CAPES), pelo auxílio durante todo o curso de mestrado. 


\section{SUMÁRIO}

Página

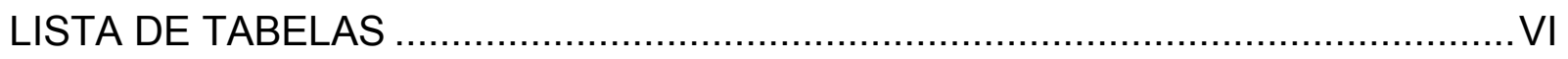

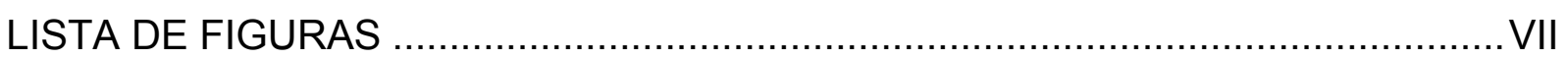

LISTA DE SIGLAS, ABREVIAÇÕES E SÍMBOLOS ............................................... VIII

RESUMO

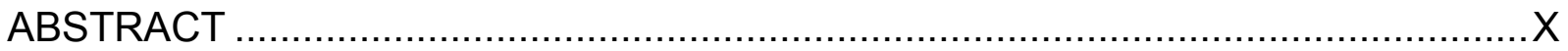

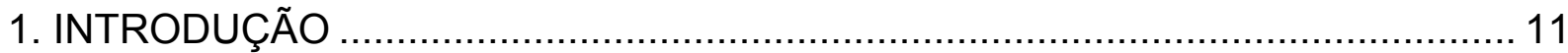

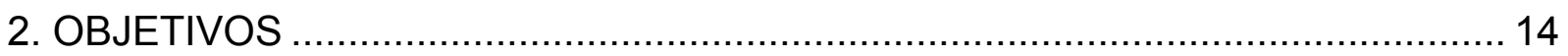

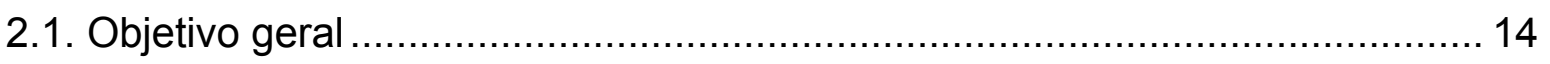

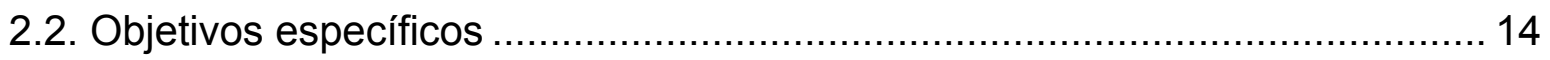

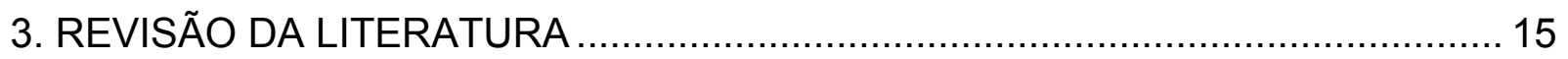

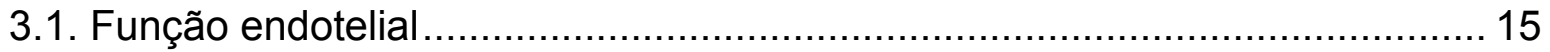

3.1.1. Endotélio vascular e mecanismos de vasodilatação .............................. 15

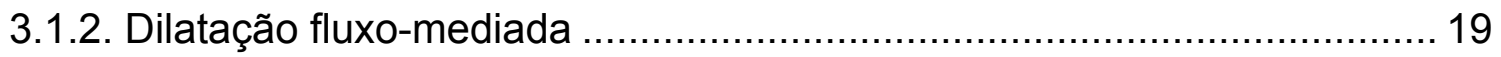

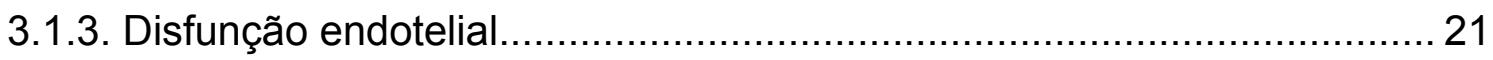

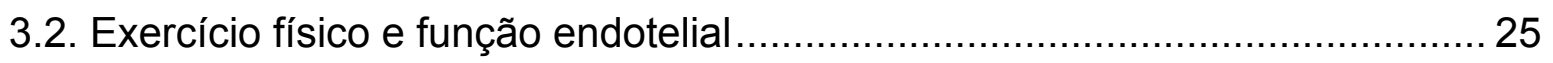

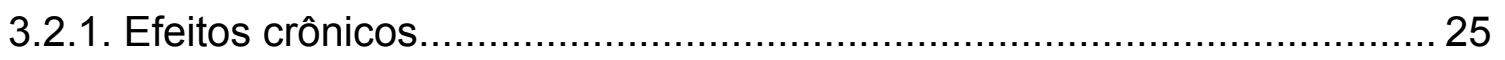

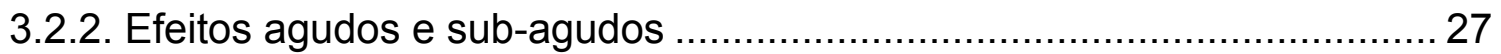

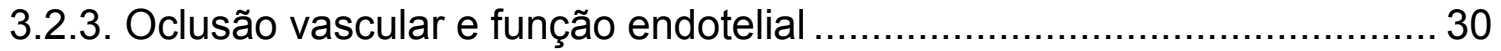

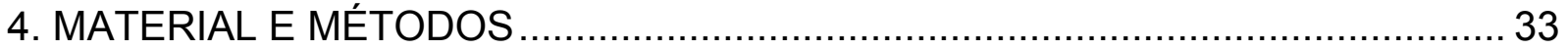

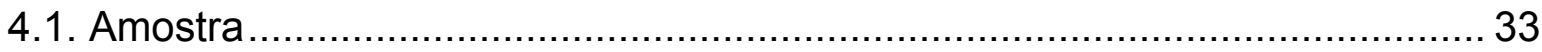

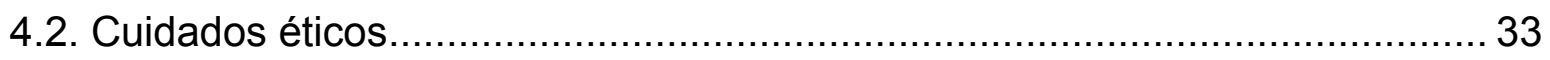

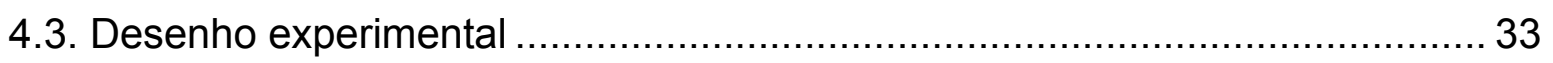

4.4. Força de preensão manual ..................................................................... 34

4.5. Dilatação fluxo-mediada e velocidade do fluxo sanguíneo ……..................... 35

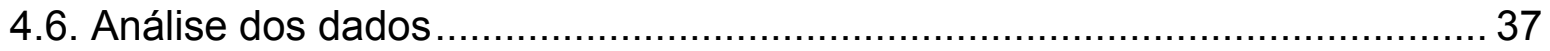

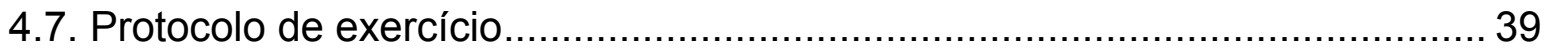




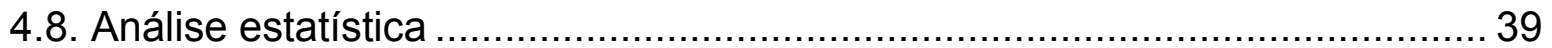

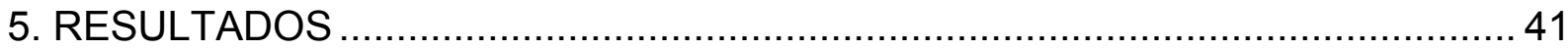

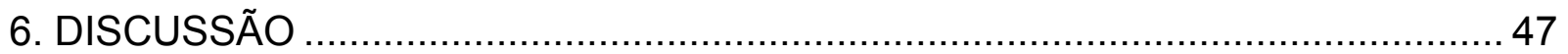

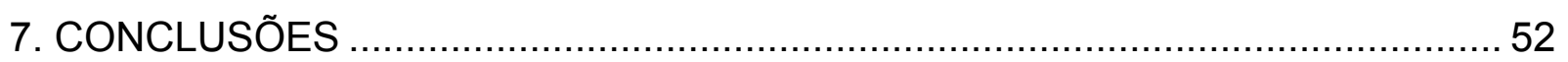

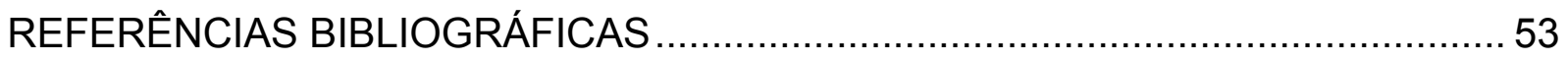

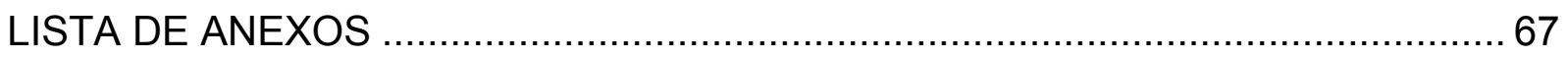

ANEXO A - TERMO DE CONSENTIMENTO LIVRE E ESCLARECIDO ..............68

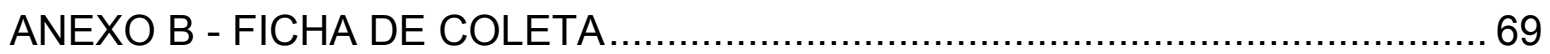


LISTA DE TABELAS

Página

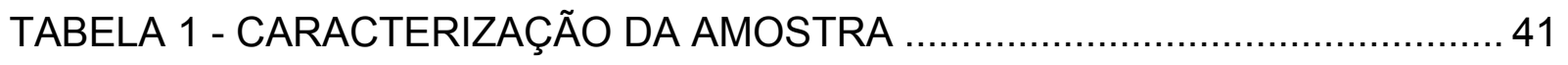

TABELA 2 - DIÂMETRO DA ARTÉRIA BRAQUIAL, TEMPO ATÉ O PICO DE DILATAÇÃO, AUC ${ }_{S R}$ E FLUXO SANGUÍNEO NO REPOUSO E APÓS A SESSÃO DE EXERCÍCIO 


\section{LISTA DE FIGURAS}

Página

FIGURA 1 - COMPONENTES DO FLUXO SANGUÍNEO NORMAL (ONDA

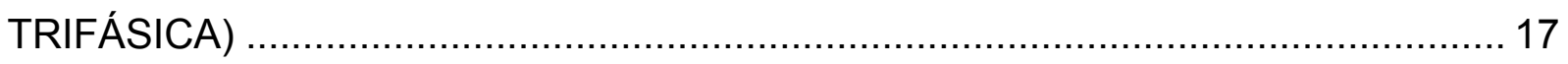

FIGURA 2 - VIAS DE VASODILATAÇÃO ENDOTÉLIO-DEPENDENTES …............. 19 FIGURA 3 - REDUÇÃO NOS FATORES DE RISCO CARDIOVASCULAR EM

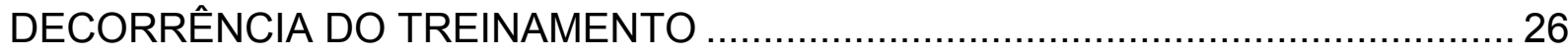

FIGURA 4 - PADRÃO DE FLUXO SANGUÍNEO EM REPOUSO, DURANTE RESTRIÇÃO DO FLUXO SANGUÍNEO E HIPEREMIA REATIVA .......................... 32

FIGURA 5 - PROCEDIMENTOS EXPERIMENTAIS ............................................. 34

FIGURA 6 - SOFTWARE UTILIZADO PARA MENSURAÇÃO DA MVC .................. 35 FIGURA 7 - AVALIAÇÃO BILATERAL DO PADRÃO DE FLUXO SANGUÍNEO DURANTE A REALIZAÇÃO DO EXERCÍCIO DE PREENSÃO MANUAL.................. 37 FIGURA 8 - IMAGEM DA ARTÉRIA BRAQUIAL GERADA PELO ULTRASSOM E UTILIZADA PARA ANÁLISES DE DIÂMETRO ARTERIAL E VELOCIDADE DE FLUXO 38

FIGURA 9 - FMD NO REPOUSO E APÓS (15 E 60 MINUTOS) O PROTOCOLO DE PREENSÃO MANUAL PARA OS BRAÇOS CON E EXP. 43 FIGURA 10 - ÍNDICE DE OSCILAÇÃO DO FLUXO EM REPOUSO E DURANTE EXERCÍCIO DE PREENSÃO MANUAL PARA OS BRAÇOS CON E EXP 44 FIGURA 11 - TAXAS DE CISALHAMENTO (MÉDIA, ANTERÓGRADA E RETRÓGRADA) NO REPOUSO E DURANTE O EXERCÍCIO DE PREENSÃO MANUAL PARA OS BRAÇOS CON E EXP...

FIGURA 12 - CORRELAÇÃO ENTRE ÍNDICE DE OSCILAÇÃO DO FLUXO E $\triangle F M D$ NO MINUTO 15 46 


\title{
LISTA DE SIGLAS, ABREVIAÇÕES E SÍMBOLOS
}

\author{
$\mathrm{AC}=$ Adelinil Ciclase \\ $\mathrm{ACh}=$ Acetilcolina \\ $\mathrm{AUC}_{\mathrm{SR}}=$ Área Sob a Curva da Taxa de Cisalhamento \\ $\mathrm{BFR}=$ Restrição do Fluxo Sanguíneo \\ $\mathrm{Ca}_{2}{ }^{+-}=$Cálcio \\ cAMP = Monofosfato de Adenosina Cíclico \\ cGMP = Monofosfato de Guanosina Cíclico \\ $\mathrm{CON}=$ Braço Controle \\ $\mathrm{COX}=$ Ciclo-Oxigenase \\ $E C=$ Célula Endotelial \\ EDRF = Fator de Relaxamento Derivado do Endotélio \\ EETs = Ácidos Epoxieicosatrienoicos \\ eNOS = Óxido Nítrico Sintase Endotelial \\ $\mathrm{EP}=$ Erro Padrão \\ $\mathrm{EXP}=$ Braço Experimental \\ $\mathrm{FMD}=$ Dilatação Fluxo-Mediada \\ $\mathrm{H} 2 \mathrm{O} 2$ = Peróxido de Hidrogênio \\ iNOS = Óxido Nítrico Sintase Induzível \\ $\mathrm{K}^{+}=$Potássio \\ $M V C=$ Contração Isométrica Voluntária Máxima \\ nNOS = Óxido Nítrico Sintase Neuronal \\ $\mathrm{NO}=$ Óxido Nítrico \\ NOS = Óxido Nítrico Sintase \\ $\mathrm{NOx}=$ Nitrito e nitrato \\ $P K A=$ Proteína Cinase $A$ \\ $P K G=$ Proteína Cinase $G$ \\ $P S E=$ Percepção Subjetiva de Esforço \\ $s G C=$ Guanilato Ciclase Solúvel \\ $\mathrm{SR}_{\mathrm{ANT}}=$ Taxa de Cisalhamento Anterógrada \\ $\mathrm{SR}_{\mathrm{ME} D I A}=$ Taxa de Cisalhamento Média \\ $\mathrm{SR}_{\mathrm{RET}}=$ Taxa de Cisalhamento Retrógrada
}




\section{RESUMO}

Objetivo: Verificar os efeitos agudos e sub-agudos do exercício de preensão manual, combinado ou não com a restrição do fluxo sanguíneo (BFR), na função endotelial de homens jovens. Métodos: Nove participantes (28 \pm 2 anos) completaram uma sessão de exercício de preensão manual bilateral, com duração de 20 minutos e intensidade de $60 \%$ da contração voluntária máxima. Para induzir a BFR um manguito foi posicionado $2 \mathrm{~cm}$ abaixo da fossa antecubital no braço experimental (EXP) e insuflado a $80 \mathrm{mmHg}$ durante o exercício. O braço EXP e o braço controle (CON) foram selecionados aleatoriamente para todos os sujeitos. $A$ dilatação fluxo-mediada da artéria braquial (FMD) e a velocidade de fluxo sanguíneo foram mensurados por meio de ultrassonografia com Doppler em três momentos distintos: repouso, 15 e 60 minutos após o término do protocolo. Adicionalmente a velocidade de fluxo sanguíneo foi analisada durante a realização do exercício. Resultados: Foi observado um aumento significativo na FMD 15 minutos após o exercício para o braço CON $(64,09 \pm 16,59 \%, P \leq 0,01)$, já no braço EXP não foram verificadas alterações $(-12,48 \pm 12,64, P=0,25)$; foi encontrada uma diferença significativa entre os dois braços neste momento $(P \leq 0,01)$. A FMD retornou a valores próximos dos iniciais 60 minutos após o exercício, sem diferença entre os braços $(P=0,42)$. Durante a realização do exercício o braço EXP apresentou valores significativamente maiores de taxa de cisalhamento retrógrada $(P \leq 0,01)$ e menor taxa de cisalhamento média $(P=0,02)$. Conclusão: Uma única sessão de exercício de preensão manual provocou uma melhora na função endotelial 15 minutos após o término do exercício, a adição de um manguito insuflado a $80 \mathrm{mmHg}$ no braço EXP aboliu esta resposta aguda.

Palavras-chaves: Restrição do fluxo sanguíneo; Função vascular; Dilatação fluxomediada; Estresse de cisalhamento. 


\begin{abstract}
Purpose: The purpose of this study was to examine the acute and sub-acute effects of handgrip exercise combined with BFR on endothelial function on healthy young men. Methods: Nine participants $(28 \pm 1.8 \mathrm{yr})$ completed a single 20 min bout of bilateral handgrip exercise with $60 \%$ of their maximum voluntary contraction. To induce BFR a cuff was placed $2 \mathrm{~cm}$ below the antecubital fossa in the experimental arm (EXP) and inflated to $80 \mathrm{mmHg}$ during the exercise bout. The EXP and control arms (CON) were randomly selected for all subjects. Brachial artery flow-mediated dilation (FMD) and blood flow velocity profiles were assessed using Doppler ultrasonography before initiation of the exercise, 15 and 60 minutes after. Blood flow velocity profiles were also assessed during the exercise. Results: There was a significant increase in FMD 15 minutes after exercise for the CON arm (64.09 \pm $16.59 \%, P \leq 0.01)$, meanwhile there was no change in the EXP arm $(-12.48 \pm 12.64$, $P=0.25)$, a significant difference was observed between both arms at this time-point $(P \leq 0.01)$. FMD returned to near baseline values at 60 minutes after exercise, with no significant difference between arms $(P=0.42)$. BFR during exercise in the EXP arm resulted in a significantly higher retrograde shear rate $(P \leq 0.01)$ and a lower mean shear rate $(P=0.02)$. Conclusion: $A$ single handgrip exercise bout provoked an acute increase on endothelial function $15 \mathrm{~min}$ after the exercise cessation, the addition of an inflated pneumatic cuff to the exercising arm abolished this acute response.
\end{abstract}

Keywords: Blood flow restriction; Vascular function; Flow-mediated dilation; Shear stress. 


\section{INTRODUÇÃO}

A prática regular de atividades físicas está associada a redução significativa do risco cardiovascular (Green et al., 2008), contribuindo na prevenção de eventos primários (Sesso et al., 2000) e secundários (Clark et al., 2005; Hambrecht et al., 2004; Hamer et al., 2012). No entanto os mecanismos pelos quais o exercício físico promove a redução na ocorrência de eventos cardiovasculares ainda não foram completamente elucidados (Hamer et al., 2012). Um estudo recente envolvendo cerca de 27,000 mulheres reportou que as alterações nos fatores de risco cardiovascular em função do nível de atividade física explicaram somente $59 \%$ da redução de risco cardiovascular (Mora et al., 2007). Diante deste quadro, foi proposto que adaptações na estrutura vascular e função endotelial em decorrência do exercício físico podem desempenhar um importante papel na prevenção de eventos cardiovasculares (Thijssen et al., 2010).

O prejuízo da função endotelial, conhecido também como disfunção endotelial, pode auxiliar no prognóstico de eventos cardiovascular (Inaba et al., 2010; Lerman; Zeiher, 2005; Suwaidi et al., 2000; Yeboah et al., 2007) e na identificação de indivíduos com alto risco de desenvolver doenças do sistema cardiovascular (Brevetti et al., 2003; Celermajer et al., 1992), além de estar associado a diversos fatores de risco cardiovascular como a dislipidemia, tabagismo, inatividade física, obesidade, pressão arterial elevada, diabetes mellitus e envelhecimento (Black et al., 2008; Celermajer et al., 1992; Schofield et al., 2002; Suzuki et al., 2008; Widlansky et al., 2003; Zhang et al., 2000). Melhoras na função endotelial demonstradas por aumentos nos valores de dilatação fluxo-mediada (FMD) veem sendo extensivamente reportadas em diversas populações após períodos de treinamento com variadas modalidades de exercício (Allen et al., 2003; Beck et al., 2013; Credeur et al., 2010), com alguns estudos demonstrando melhoras significativas após somente 2 semanas (Dobrosielski et al., 2009; Tinken et al., 2010).

Apesar do exercício físico tradicional promover adaptações benéficas na função endotelial foi verificado que a utilização do método de oclusão vascular em conjunto com a atividade física é capaz de atenuar ou até abolir estas adaptações (Hunt et al., 2012; Tinken et al., 2010), com um estudo recente reportando 
decréscimo de aproximadamente $30 \%$ nos valores de FMD após 4 semanas de treinamento combinado com a oclusão vascular (Credeur et al., 2010). Este método de treinamento se baseia na utilização de um manguito insuflado no membro que está realizando o exercício, causando uma restrição do fluxo sanguíneo (BFR) ao músculo ativo e redução do retorno venoso, induzindo ganhos de força e massa muscular de magnitude comparável, ou maior, do que o treinamento tradicional (Fry et al., 2010; Takarada et al., 2000). Entretanto a BFR impede os aumentos na velocidade de fluxo sanguíneo e taxas de cisalhamento observadas durante o exercício, que foram previamente demonstrados como os principais estímulos fisiológicos para as adaptações na função endotelial associada ao treinamento físico (Tinken et al., 2009; Tinken et al., 2010). Aumentos nas taxas de cisalhamento média e anterógrada estão associadas a adaptações benéficas na estrutura e função do endotélio vascular (Naylor et al., 2011; Tuttle et al., 2001), servindo também como um importante estímulo para a dilatação das artérias condutoras durante o exercício (Padilla et al., 2011b). Adicionalmente insuflar um manguito promove aumentos na taxa de cisalhamento retrógrada de maneira dose-dependente, este componente do fluxo sanguíneo é considerado prejudicial ao endotélio e pode levar ao detrimento das adaptações benéficas em resposta ao exercício (Credeur et al., 2010; Schreuder et al., 2014; Thijssen et al., 2009).

Os aumentos agudos na função endotelial após uma única sessão de exercício também são afetados pela BFR. Os estudos que reportaram aumentos significativos na FMD demonstraram que a adição da BFR inibiu as repostas agudas somente para o braço ocluído (Tinken et al., 2009; Tinken et al., 2010). De maneira sub-aguda maiores valores de FMD foram observados 1 hora após uma única sessão de exercício (Atkinson et al., 2015; Harris et al., 2008), além de aumentos na reatividade vascular (Bousquet-Santos et al., 2005), no entanto os efeitos subagudos do exercício combinado com a BFR ainda não estão claros. Levando em consideração que as adaptações ao exercício físico podem resultar da soma das respostas agudas e sub-agudas (Da Nobrega, 2005) é importante entender os efeitos do exercício na FMD nas horas subsequentes ao término da sessão. Diante deste quadro, o presente trabalho teve como objetivo verificar os efeitos agudos e subagudos do exercício de preensão manual, combinado ou não com a restrição do 
fluxo sanguíneo, na função endotelial de homens jovens. Foi levantada a hipótese de que as alterações no padrão de fluxo sanguíneo e nas taxas de cisalhamento causados pela BFR durante o exercício seriam prejudiciais aos efeitos agudos e subagudos do exercício na função endotelial. 


\section{OBJETIVOS}

\subsection{Objetivo geral}

Verificar os efeitos agudos e sub-agudos do exercício de preensão manual, combinado ou não com a restrição do fluxo sanguíneo, na função endotelial de homens jovens.

\subsection{Objetivos específicos}

Verificar os efeitos sub-agudos do exercício de preensão manual combinado ou não com a restrição do fluxo sanguíneo no diâmetro de artéria braquial, tempo até o pico de dilatação, área sob a curva da taxa de cisalhamento e fluxo sanguíneo.

Verificar os efeitos agudos do exercício de preensão manual combinado ou não com a restrição do fluxo sanguíneo no índice de oscilação do fluxo sanguíneo e nas taxas de cisalhamento média, anterógrada e retrógrada durante o exercício de preensão manual com ou sem restrição do fluxo sanguíneo.

Verificar a associação entre a magnitude de aumento nos valores de dilatação fluxo-mediada e o índice de oscilação do fluxo sanguíneo e taxas de cisalhamento média, anterógrada e retrógrada durante o exercício. 


\section{REVISÃO DA LITERATURA}

\subsection{Função endotelial}

3.1.1. Endotélio vascular e mecanismos de vasodilatação

O endotélio vascular é formado por uma camada de células endoteliais que reveste internamente a parede dos vasos sanguíneos, compondo a túnica íntima (Pasyk; Jakobczak, 2004). O endotélio pode ser caracterizado como contínuo, fenestrado ou descontínuo de acordo com diferenças estruturais nas células endoteliais; o endotélio contínuo está presente nas artérias, veias e capilares do cérebro, pele, coração e pulmões, já o fenestrado pode ser encontrado nos capilares de glândulas exócrinas e endócrinas, mucosa gastrointestinal, plexos coroide, glomérulos e túbulos renais, por fim o endotélio descontínuo é comum no fígado (Aird, 2007). Diversas funções são atribuídas ao endotélio vascular, sendo que este pode atuar na permeabilidade do vaso sanguíneo, processo inflamatório, controle do estresse oxidativo, coagulação sanguínea, agregação de plaquetas e controle do tônus vasomotor (Endemann; Schiffrin, 2004; Pasyk; Jakobczak, 2004).

O papel essencial das células endoteliais no controle do tônus vascular foi primeiramente demonstrado por Furchgott e Zawadzki (1980), a partir de estudos com secções aórticas de coelhos os autores verificaram que a presença do tecido endotelial intacto era necessária para que ocorresse a vasodilatação após a exposição do vaso a acetilcolina (ACh), de modo que a retirada deste tecido resultava em uma resposta vasoconstrictora. Este estudo pioneiro propôs a existência de uma substância vasoativa liberada pelas células endoteliais na presença de ACh que seria responsável pelo relaxamento da musculatura lisa vascular e consequente vasodilatação, esta substância foi posteriormente denominada Fator de Relaxamento Derivado do Endotélio (Endothelium Derived Relaxing Factor - EDRF). Alguns anos após este estudo foi descoberto que a substância vasodilatadora liberada pelo endotélio vascular era o gás óxido nítrico (NO) devido as inúmeras semelhanças bioquímicas observadas entre as duas substâncias (Ignarro et al., 1987; Palmer et al., 1987) 
O NO é um gás solúvel altamente instável com meia vida de aproximadamente 3 a 5 segundos, podendo ser considerado uma das principais substâncias vasoativas produzidas pelo endotélio (Bredt, 1999; Tousoulis et al., 2012). Este gás é sintetizado continuamente nas células endoteliais a partir do aminoácido L-arginina pela ação da enzima óxido nítrico sintase (NOS), tendo como subproduto a L-citrulina (Bredt, 1999; Palmer et al., 1988). A enzima NOS apresenta três isoformas, são elas: NOS neuronal (nNOS ou Isoforma I), NOS endotelial (eNOS ou Isoforma III) e NOS induzível (iNOS ou Isoforma II); as duas primeiras isoformas são classificadas como enzimas constitutivas, presentes principalmente no tecido endotelial e nos tecidos do sistema nervoso, respectivamente, já a terceira isoforma tem a sua expressão mediada pela ação do sistema imunológico (Bredt, 1999; Forstermann et al., 1991; Stuehr, 1997). A eNOS é a principal enzima responsável pela síntese de NO em vasos sanguíneos saudáveis, atuando principalmente por mecanismos cálcio $\left(\mathrm{Ca}_{2}{ }^{+-}\right)$dependentes (Busse; Mulsch, 1990), no entanto já foi demonstrado que estas enzimas também podem atuar de maneira independente do $\mathrm{Ca}_{2}^{+-}$(Ayajiki et al., 1996). Após sintetizado o NO promove vasodilatação ao ativar a enzima guanilato ciclase que catalisa a conversão de trifosfato de guanosina para monofosfato de guanosina cíclico (cGMP) (Ignarro et al., 1987; Kang, 2014), na musculatura lisa vascular a molécula de cGMP tem como alvo principal a proteínacinase $G$ ou proteína-cinase cGMP dependente (cGKI), que por sua vez ativa a fosfatase da cadeia leve de miosina causando o relaxamento da musculatura (Kang, 2014; Kemp-Harper; Schmidt, 2009; Koeppen et al., 2004). A molécula de cGKI também pode influenciar a função endotelial por meio da fosforilação e ativação da eNOS (Butt et al., 2000).

A síntese de NO pela eNOS pode ser mediada por diversas substâncias vasoativas, entre elas a ACh, bradicinina, histamina, serotonina, adenosina difosfato e noradrenalina (Tousoulis et al., 2012). Além das substâncias supracitadas as células endoteliais são altamente responsivas a estímulos mecânicos, respondendo a forças de estresse circunferencial, estresse normal causado pela pressão arterial e estresse de cisalhamento causado pelo fluxo sanguíneo (Chien, 2007; Langille; O'donnell, 1986; Pohl et al., 1986). O estresse de cisalhamento é um importante estímulo fisiológico para a síntese e liberação de NO pela eNOS (Rubanyi et al., 
1986; Tousoulis et al., 2012), podendo também influenciar na expressão desta enzimas no tecido endotelial (Tuttle et al., 2001) e provocar alterações estruturais nas células endoteliais (Aird, 2007). A força tangencial causada na parede do vaso pelo fluxo sanguíneo pode ser quantificada pela fórmula $S S=4 \eta \dot{Q} / \pi R_{i}^{3}$, na qual $S S$ representa o estresse de cisalhamento, $\dot{Q}$ representa o débito cardíaco, $\eta$ representa a viscosidade do sangue e $R_{i} \circ$ raio interno do vaso (Laughlin et al., 2008). Alterações no padrão de fluxo podem alterar criticamente as respostas do endotélio ao estresse de cisalhamento, o fluxo sanguíneo normal é representado por uma onda trifásica (Figura 1), sendo composto por fluxo anterógrado rápido durante a sístole, fluxo retrógrado no início da diástole e novamente fluxo anterógrado ao final da diástole (Donnelly et al., 2000). O componente anterógrado do fluxo está associado a adaptações funcionais benéficas e quadros anti-aterogênicos (Naylor et al., 2011; Tuttle et al., 2001), já o retrógrado está relacionado a prejuízos funcionais e quadros pró-aterogênicos (Schreuder et al., 2015; Thijssen et al., 2009). Cabe também ressaltar que o fluxo laminar unidirecional está associado a melhoras funcionais e respostas anti-aterogênicas, já um aumento na oscilação do fluxo promove um estado pró-aterogênico (Laughlin et al., 2008). O estresse de cisalhamento promove a abertura de canais de íons presentes na membrana das células endoteliais, causando influxo de $\mathrm{Ca}_{2}{ }^{+-}$para o espaço intracelular e consequente síntese de NO pela eNOS (Busse; Mulsch, 1990; Gautam et al., 2006).

FIGURA 1 - Componentes do fluxo sanguíneo normal, representado por uma onda trifásica. Adaptado de Donnelly et al. (2000).

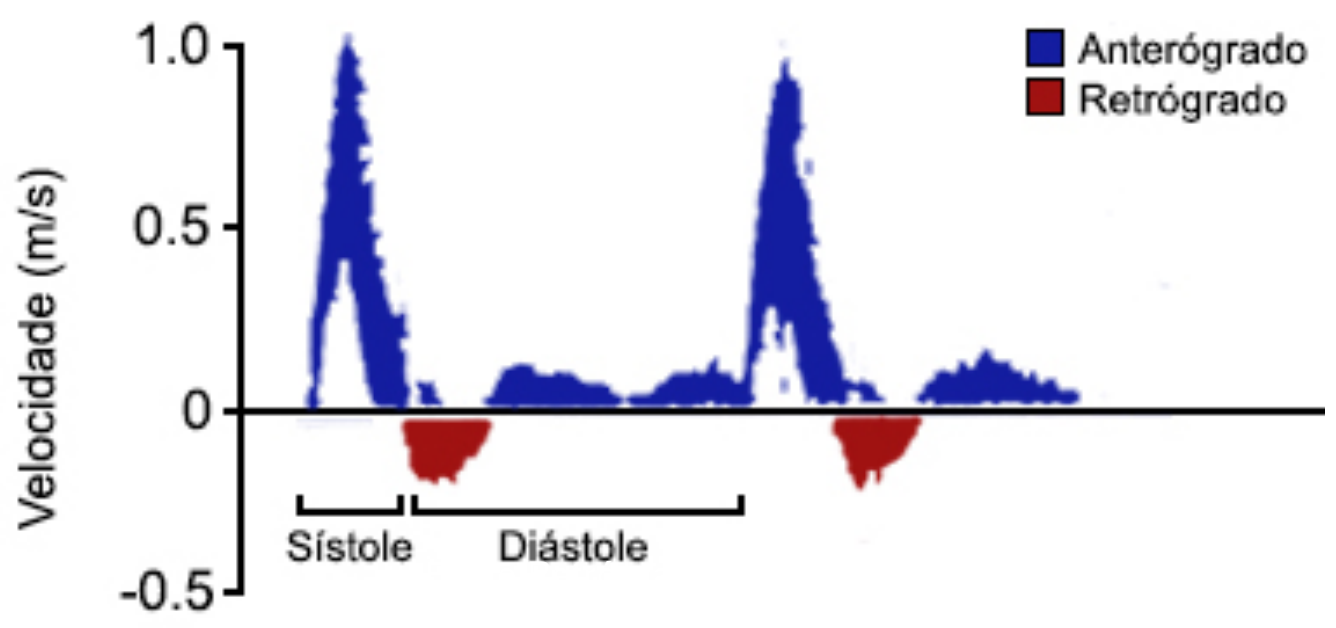


Além do NO as células endoteliais sintetizam outras substâncias vasodilatadoras em resposta ao estresse de cisalhamento, como a prostaciclina (PGI2) e o fator de hiperpolarização derivado do endotélio (Endothelium Derived Hyperpolarizing Factor - EDHF), de modo que o termo EDRF veem sendo comumente utilizado para designar o conjunto destas substâncias (Kang, 2014; Rubanyi et al., 1986). A PGI2 é sintetizada nas células endoteliais pela ação da enzima ciclo-oxigenase sobre o ácido araquidônico, após sintetizada a molécula de PGI2 atravessa a membrana da célula endotelial e se liga a receptores específicos na membrana plasmática das células musculares lisas, ativando a via de sinalização adenilil ciclase / monofosfato de adenosina cíclico / proteína cinase A (PKA), a PKA ativada faz a fosforilação de proteínas alvo na musculatura lisa resultando em vasodilatação (Kang, 2014). A síntese de PGI2 no endotélio vascular é dependente da disponibilidade de ácido araquidônico, que por sua vez depende da concentração de cálcio intracelular, sendo assim o estresse de cisalhamento também representa um importante estímulo para a síntese de PGI2 devido a abertura dos canais de íons presentes na membrana das células endoteliais e consequente influxo de CA2+- para o espaço intracelular (Gautam et al., 2006).

O EDHF por sua vez pode ser definido como um conjunto de fatores produzidos pelo endotélio vascular que causam a hiperpolarização da musculatura lisa vascular e consequentemente o relaxamento (Luksha et al., 2009). Diversos mecanismos podem explicar a hiperpolarização da células musculares, entre eles íons de $\mathrm{K}^{+}$, peróxido de hidrogênio $\left(\mathrm{H}_{2} \mathrm{O}_{2}\right)$, ácidos epoxieicosatrienoicos (EETs) e junções de hiato. A atuação destes mecanismos está baseada na abertura de canais de $\mathrm{K}^{+}$presentes na membrana da célula muscular causando o efluxo deste íon do espaço intracelular, levando a hiperpolarização; a alteração no potencial da membrana reduz o influxo de $\mathrm{Ca}_{2}{ }^{+-}$causando relaxamento da musculatura (Kang, 2014). Os mecanismos de vasodilatação dependentes do endotélio estão resumidos na Figura 2.

Atualmente é proposto que as três vias de vasodilatação endotéliodependentes supracitadas funcionam de maneira complementar, sendo que a inibição de uma das vias pode induzir maior ativação das outras através de mecanismos compensatórios (Bellien et al., 2006; Markwald et al., 2011). É também 
necessário ressaltar a possiblidade de diferentes fenótipos das células endoteliais em resposta ao estresse de cisalhamento, existindo portanto diferenças individuais na atuação destes mecanismos (Parker et al., 2011; Pyke, K. et al., 2010).

FIGURA 2 - Vias de vasodilatação endotélio-dependentes.

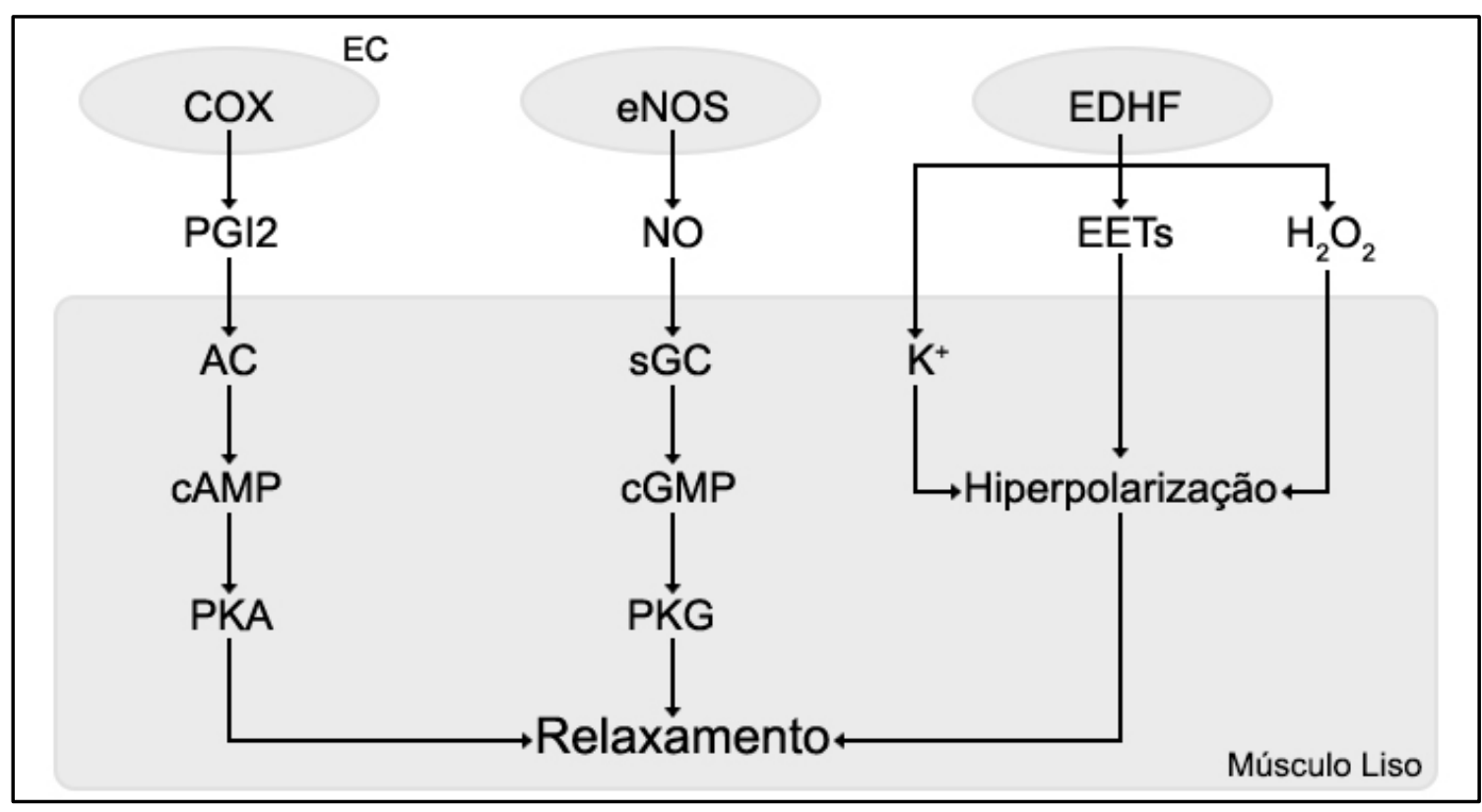

$\mathrm{EC}=$ célula endotelial $; \mathrm{COX}=$ ciclo-oxigenase $; \mathrm{AC}=$ adenilil ciclase $; \mathrm{cAMP}=$ monofosfato de adenosina cíclico; $\mathrm{PKA}=$ proteína cinase $\mathrm{A}$; eNOS = óxido nítrico sintase endotelial, $\mathrm{sGC}=$ guanilato ciclase solúvel; $c G M P=$ monofosfato de guanosina cíclico; PKG = proteína cinase $\mathrm{G}$; EDHF = fator de hiperpolarização derivado do endotélio; $\mathrm{K}^{+}=$íons de potássio; EETs = ácidos epoxieicosatrienoicos; $\mathrm{H}_{2} \mathrm{O}_{2}=$ peróxido de hidrogênio.

\subsubsection{Dilatação fluxo-mediada}

Baseado nos mecanismos de vasodilatação endotélio-dependentes supracitados, em especial na via NO/cGMP/cGKI, Celermajer et al. (1992) desenvolveram uma técnica não-invasiva de avaliação da função endotelial denominada dilatação fluxo-mediada (FMD) visando identificar a presença de disfunção endotelial em indivíduos com alto risco de desenvolver aterosclerose antes de qualquer manifestação clínica da doença. Atualmente este método pode ser utilizado para auxiliar no prognóstico de doenças que acometem o sistema cardiovascular como a doença arterial periférica (Brevetti et al., 2003), doença 
arterial coronariana (Suwaidi et al., 2000) e aterosclerose (Celermajer et al., 1992), além de apresentar uma alta relação com a função endotelial das artérias condutoras (i.e. coronárias) mensurada de maneira invasiva (Anderson et al., 1995).

A técnica consiste na utilização de ultrassonografia para quantificar o diâmetro de artérias superficiais em repouso e após um período de fluxo sanguíneo elevado (hiperemia reativa), de modo que a diferença entre as duas mensurações serve como indicativo da função endotelial. A hiperemia reativa é induzida utilizando um manguito insuflado a níveis supra-sistólicos com o objetivo de causar uma restrição do fluxo sanguíneo (BFR) na artéria avaliada durante determinado período de tempo. A hipóxia tecidual causada pela oclusão leva a vasodilatação devido a fatores miogênicos e a produção de metabólitos (Crecelius et al., 2013), consequentemente ocorre redução da resistência vascular e a liberação da pressão no manguito leva a um aumento súbito do fluxo sanguíneo e estresse de cisalhamento (Corretti et al., 2002; Harris et al., 2010). Inicialmente acreditava-se que o NO era o principal responsável pela vasodilatação observada após o protocolo de FMD, no entanto diversos estudos recentes verificaram que a inibição da síntese de NO não aboliram completamente a resposta vasodilatadora, sendo proposto que a PGI2 e os EDHFs também podem contribuir para a vasodilatação (Bellien et al., 2006; Doshi et al., 2001; Mullen et al., 2001; Parker et al., 2011; Pyke, K. et al., 2010; Wray et al., 2013). Estudos recentes sugerem que diferenças individuais podem alterar a contribuição relativa dos mecanismos de vasodilatação durante o método de FMD (Parker et al., 2011; Pyke, K. et al., 2010). É possível verificar na literatura diversas variações do protocolo original proposto por Celermajer et al. (1992), incluindo alterações no local de mensuração, posicionamento do manguito e tempo de oclusão, podendo influenciar tanto nos valores de FMD quanto na contribuição relativa das vias de vasodilatação. O local de mensuração utilizado para análise afeta diretamente os resultados devido a correlação inversa entre os valores de FMD e o diâmetro da artéria em repouso (Celermajer et al., 1992; Corretti et al., 2002; Zhang et al., 2000), sendo indicado a utilização de artérias de calibre inferior a 6 milímetros como as artérias braquial e femoral superficial. $\mathrm{O}$ posicionamento do manguito e tempo de oclusão afetam, além dos valores encontrados, a contribuição das vias de vasodilatação, de modo que a colocação do manguito distal (punho ou antebraço) e 
menores tempos de oclusão estão associados a maior participação da via do $\mathrm{NO}$ e menor valor de FMD, já o manguito proximal (braço) e tempo de oclusão prolongado levam a menor contribuição do NO e maiores valores de FMD, além de possível vasodilatação de maneira independente do endotélio (Doshi et al., 2001; Harris et al., 2010; Mullen et al., 2001; Pyke, K. et al., 2010; Tousoulis et al., 2005; Wray et al., 2013). Portanto para a análise da função endotelial é recomendado que se realize oclusão de 5 minutos com manguito posicionado no punho ou antebraço (Corretti et al., 2002; Harris et al., 2010; Pyke, K. E.; Tschakovsky, 2005). Outros fatores que podem influenciar os resultados são a alimentação, utilização de medicamentos que afetem o sistema cardiovascular e a realização de atividades físicas em períodos próximos a mensuração (Corretti et al., 2002; Harris et al., 2010).

A utilização do método de FMD visando estudar os efeitos sub-agudas do exercício envolve a realização de várias mensurações em um curto período de tempo, no entanto já foi reportado na literatura que um intervalo mínimo de 10 minutos entre as medidas é suficiente para garantir o retorno dos parâmetros ao estado inicial (Corretti et al., 2002; Doshi et al., 2001; Pyke, K. et al., 2010), com apenas uma recomendação de 30 minutos de intervalo (Harris et al., 2010). Adicionalmente a avaliação bilateral por meio da FMD também já foi estudada, sendo reportado que a oclusão vascular em um membro não afeta de maneira significativa os valores de FMD ou a velocidade de fluxo sanguíneo no membro contralateral (Mullen et al., 2001; Thijssen et al., 2010).

\subsubsection{Disfunção endotelial}

A disfunção endotelial é caracterizada principalmente por prejuízos na capacidade de vasodilatação em resposta a estímulos específicos como a ACh e o estresse de cisalhamento, no entanto este conceito pode ser expandido para incluir a presença de um estado pró-inflamatório e pro-trombótico (Cai; Harrison, 2000; 
Endemann; Schiffrin, 2004; Widlansky et al., 2003). A disfunção endotelial apresenta importante função no prognóstico de eventos cardiovasculares (Inaba et al., 2010; Lerman; Zeiher, 2005; Suwaidi et al., 2000; Yeboah et al., 2007) e também na identificação de indivíduos com alto risco de desenvolver doenças do sistema cardiovascular, como a aterosclerose e a doença arterial periférica (Brevetti et al., 2003; Celermajer et al., 1992). Muitos fatores de risco cardiovascular já foram associados a prejuízos na função endotelial, como a dislipidemia, tabagismo, inatividade física, obesidade, pressão arterial elevada, diabetes mellitus e envelhecimento (Black et al., 2008; Celermajer et al., 1992; Schofield et al., 2002; Suzuki et al., 2008; Widlansky et al., 2003; Zhang et al., 2000).

A hipertensão arterial, doença que acomete aproximadamente $30 \%$ da população brasileira (Picon et al., 2012), está associada com o quadro de disfunção endotelial, sendo possível verificar em indivíduos diagnosticados com esta doença resposta vasodilatadora prejudicada tanto ao estímulo da FMD (Beck et al., 2013; Zhang et al., 2000) quanto a exposição a substâncias vasoativas como a ACh e a bradicinina (Panza et al., 1990; Park et al., 2001; Park; Schiffrin, 2001; Rizzoni et al., 2001). A disfunção endotelial observada na hipertensão arterial foi atribuída a menor síntese de substâncias vasodilatadoras pelas células endoteliais, como o NO e a PGI2, além de maior produção de substâncias vasoconstrictoras (Beck et al., 2013; Panza et al., 1990), sendo também proposto que um quadro de estresse oxidativo elevado causa a menor biodisponibilidade do NO (Cai; Harrison, 2000). Além de prejuízos funcionais indivíduos diagnosticados com hipertensão arterial apresentam alterações estruturais prejudiciais nos vasos sanguíneos, como aumento da área de secção transversa da túnica média e redução do lúmen (Park et al., 2001; Park; Schiffrin, 2001; Rizzoni et al., 2001; Schofield et al., 2002). Outras doenças do sistema cardiovascular, como a doença arterial coronariana e a doença arterial periférica, também estão ligadas a disfunção endotelial (Brevetti et al., 2003; Celermajer et al., 1992; Suwaidi et al., 2000; Zhang et al., 2000).

A diabetes mellitus também pode levar ao quadro de disfunção endotelial, de modo que indivíduos diagnosticados com esta doença apresentam resposta vasodilatadora prejudicada em resposta a ACh e bradicinina (Rizzoni et al., 2001; Schofield et al., 2002) e também menores valores de FMD (Henry et al., 2004). 
Assim como na hipertensão arterial, a diabetes é acompanhada de alterações estruturais nos vasos sanguíneos, ocorrendo aumento da espessura da túnica média, aumento do conteúdo de colágeno no músculo e redução do lúmen (Rizzoni et al., 2001; Schofield et al., 2002). Em relação a síndrome metabólica existem resultados controversos na literatura, sendo possível verificar estudos que identificaram valores menores de FMD em sujeitos classificados com síndrome metabólica quando comparados com controle (Suzuki et al., 2008), no entanto outros estudos não encontraram esta associação (Aizawa et al., 2009; Fernandes et al., 2014). É interessante destacar que apesar dos valores de FMD não divergirem no estudo de Fernandes et al. (2014), os sujeitos com síndrome metabólica apresentavam maior tempo até o pico de dilatação, variável que está associada a prejuízos na função endotelial e aumentado risco cardiovascular (Black et al., 2008; Padilla et al., 2009).

O processo natural de envelhecimento também está associado a prejuízos na função endotelial, com estudos reportando valores de FMD significativamente menores em indivíduos idosos quando comparados com jovens (Schreuder et al., 2015; Zhang et al., 2000), sendo observada uma correlação inversa entre os valores de FMD e a idade (Welsch et al., 2008). Também já foi verificado maior tempo até o pico de vasodilatação em indivíduos idosos (Black et al., 2008), que está associado a aumentado risco cardiovascular conforme mencionado anteriormente (Padilla et al., 2009). O avançar da idade promove alterações no padrão de fluxo sanguíneo, acarretando em aumento do fluxo retrógrado de aproximadamente $60 \%$ por década após os 60 anos de idade (Credeur et al., 2009), este padrão de fluxo está associado a prejuízos na função endotelial (Schreuder et al., 2014; Thijssen et al., 2009). Schreuder et al. (2015) propuseram que indivíduos idosos apresentam células endoteliais menos responsivas aos estímulos de cisalhamento, no entanto estudos que avaliaram os efeitos agudos e crônicos do exercício, que são altamente dependentes do estresse de cisalhamento, verificaram que essa população ainda tem capacidade de responder a estes estímulos (Dobrosielski et al., 2009; Harvey et al., 2005). É interessante destacar que a disfunção endotelial em indivíduos idosos esta associada com uma redução da performance funcional, ou seja, menor 
capacidade de realizar atividades da vida diária (Credeur et al., 2009; Welsch et al., 2008). 


\subsection{Exercício físico e função endotelial}

\subsubsection{Efeitos crônicos}

A prática regular de exercícios físicos é capaz de reduzir o risco cardiovascular de maneira significativa, podendo ser associada a redução de aproximadamente $30 \%$ no risco cardiovascular (Green et al., 2008). Um estudo recente envolvendo 27,055 mulheres saudáveis demonstrou que as alterações nos fatores de risco tradicionais explicam somente $59 \%$ da redução de risco cardiovascular associado com o exercício (Figura 3 ), sugerindo que aproximadamente $40 \%$ da redução de risco não pode ser explicada pelos fatores de risco cardiovascular (Mora et al., 2007). Diante deste quadro, foi proposto que as adaptações na função endotelial decorrentes da prática de exercícios físicos possuem um importante papel na redução do risco cardiovascular, no entanto esta contribuição ainda não foi quantificada (Thijssen et al., 2010).

O exercício físico realizado de maneira sistematizada é capaz de promover adaptações positivas na função endotelial em indivíduos de diversas populações, sendo possível verificar aumentos nos valores de FMD após um curto período de treinamento (Allen et al., 2003; Beck et al., 2013; Credeur et al., 2010), com estudos reportando melhoras significativas de até $30 \%$ na função endotelial após somente 2 semanas (Dobrosielski et al., 2009; Tinken et al., 2010). No entanto alguns estudos não reportaram aumentos na FMD após o treinamento (Aizawa et al., 2009; Hunt et al., 2012), esses resultados podem estar associados a diferenças no protocolo de treino empregados ou na população estudada, Hunt et al. (2012) por exemplo utilizaram uma intensidade de $40 \%$ da contração voluntária máxima (MVC), muito abaixo da utilizada nos demais estudos. Apesar de não ser claramente demonstrado na literatura a associação entre intensidade do exercício e as adaptações na função endotelial, é possível verificar que existe essa associação em estudos agudos e subagudos (Atkinson et al., 2015; Johnson et al., 2012), de modo que diferenças nas variáveis do treinamento podem influenciar também os efeitos crônicos. 
FIGURA 3 - Redução nos fatores de risco cardiovascular em decorrência do treinamento. Adaptado de Thijssen et al. (2010).

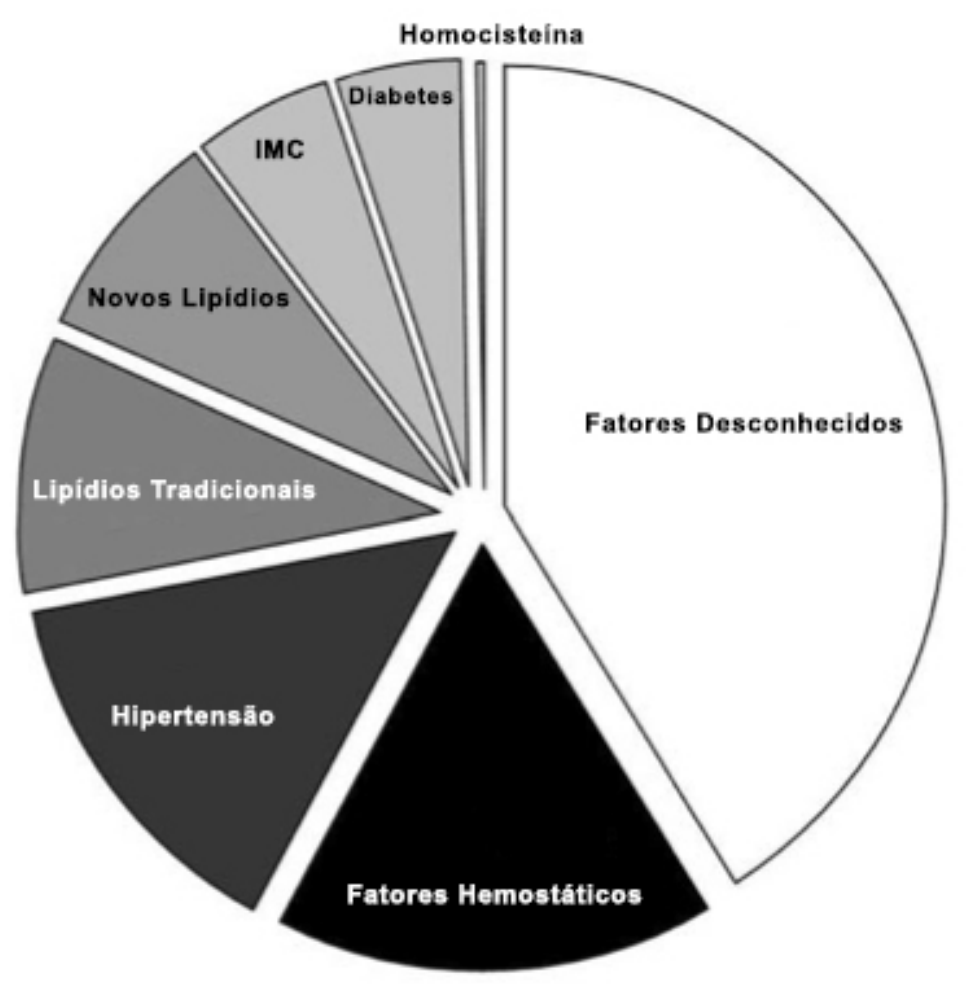

As alterações agudas no padrão de fluxo sanguíneo e taxas de cisalhamento em decorrência da prática de atividade física são consideradas como o principal estímulo para as adaptações observadas na função endotelial (Credeur et al., 2010; Laughlin et al., 2008; Naylor et al., 2011; Tinken et al., 2009; Tinken et al., 2010). Durante a realização do exercício física é possível observar aumentos nas taxas de cisalhamento média e anterógrada (Atkinson et al., 2015; Credeur et al., 2010; Padilla et al., 2011b) que estão associadas a adaptações positivas na função endotelial (Naylor et al., 2011; Tuttle et al., 2001). Já o componente retrógrado, considerado como prejudicial a função endotelial (Schreuder et al., 2015; Thijssen et al., 2009), apresenta diferentes comportamentos de acordo com a modalidade de exercício empregada, sendo possível verificar tanto aumento (Padilla et al., 2011b; Tinken et al., 2009; Tinken et al., 2010) quanto manutenção (Atkinson et al., 2015; Credeur et al., 2010) da taxa de cisalhamento retrógrado durante o exercício. 
Adicionalmente o treinamento pode promover adaptações de outras variáveis relacionadas a função endotelial. Credeur et al. (2010) reportaram aumento da área sob a curva da taxa de cisalhamento ( $\left(\mathrm{UUC}_{\mathrm{SR}}\right.$ ), estímulo para a vasodilatação durante o protocolo de FMD, após 4 semanas de treinamento de preensão manual, no entanto diversos estudos não verificaram diferenças significativas nessa variável após o treino (Dobrosielski et al., 2009; Hunt et al., 2012; Tinken et al., 2010). É possível verificar também alterações na biodisponibilidade de substâncias vasoativas e redução de substâncias vasoconstrictoras circulantes em resposta a prática de atividades físicas. Beck et al. (2013) reportaram aumentos significativos nas concentrações plasmáticas de metabólitos do $\mathrm{NO}$ e da PGI2 após o treinamento acompanhados de maiores valores de FMD, além de uma redução das concentrações de endotelina-1. Os autores ainda demonstraram uma correlação positiva entre os metabólitos do NO e FMD, e uma correlação negativa entre endotelina-1 circulante e FMD. Cabe ressaltar que protocolos de vasodilatação independentes do endotélio, como por exemplo pela utilização de gliceril trinitato, não apresentam melhoras significativas em decorrência do treinamento (Naylor et al., 2011; Tinken et al., 2010).

Após períodos prolongados de treinamento é possível observar uma resposta bifásica da FMD, de modo que os valores aumentam significativamente nas primeiras semanas e retornam a valores próximos dos iniciais nas semanas subsequentes (Naylor et al., 2011; Tinken et al., 2010), essa redução observada nos valores de FMD é acompanhada de adaptações estruturais conforme indicado pela resposta ao protocolo de exercício isquêmico (Naylor et al., 2005). É interessante destacar que o diâmetro arterial durante o repouso não é alterado em função do treinamento (Beck et al., 2013; Credeur et al., 2010; Dobrosielski et al., 2009; Hunt et al., 2012; Tinken et al., 2010).

\subsubsection{Efeitos agudos e sub-agudos}

Os efeitos agudos e sub-agudos do exercício físicos na função endotelial ainda não estão completamente elucidados na literatura, sendo possível verificar divergências nos estudos publicados acerca dessas respostas. Estudos que 
buscaram avaliar a FMD após uma única sessão de exercício físico verificaram aumentos significativos imediatamente após o término da sessão (Johnson et al., 2012; Tinken et al., 2009; Tinken et al., 2010), aumentos 1 hora após (Atkinson et al., 2015; Harris et al., 2008; Harvey et al., 2005), manutenção dos valores de FMD (Dawson et al., 2008; Harvey et al., 2005; Johnson et al., 2012; Jones et al., 2010), e alguns verificaram reduções significativas (Dawson et al., 2008; Harris et al., 2008; Jones et al., 2010). Em função dos resultados divergentes encontrados na literatura é consenso que os efeitos agudos e sub-agudos do exercício físico na função endotelial podem ser influenciados tanto pelo protocolo empregado (Atkinson et al., 2015; Johnson et al., 2012; King et al., 2013) quanto pelo população estudada (Harris et al., 2008; Harvey et al., 2005), sendo necessário reiterar que diferenças no método de FMD entre os estudos também podem afetar drasticamente os resultados encontrados (ver tópico 3.1.2.).

Assim como nos efeitos crônicos, as alterações agudas na velocidade e padrão de fluxo sanguíneo durante a realização do exercício são consideradas como o principal estímulo para as respostas agudas e sub-agudas da função endotelial (Padilla et al., 2011b; Tinken et al., 2009; Tinken et al., 2010). Modulações no estresse de cisalhamento independente do estímulo do exercício são capazes de induzir aumentos agudos na FMD (Naylor et al., 2011), além de promover vasodilatação de artérias condutoras em membros inativos durante o exercício (Padilla et al., 2011b). Conforme mencionado anteriormente, durante a realização do exercício física é possível observar aumentos nas taxas de cisalhamento média e anterógrada (Atkinson et al., 2015; Credeur et al., 2010; Padilla et al., 2011b), que estão associadas a adaptações positivas na função endotelial (Naylor et al., 2011; Tuttle et al., 2001). Já o componente retrógrado, considerado como prejudicial a função endotelial (Schreuder et al., 2015; Thijssen et al., 2009), apresenta diferentes comportamentos de acordo com a modalidade de exercício empregada, sendo possível verificar tanto aumento (Padilla et al., 2011b; Tinken et al., 2009; Tinken et al., 2010) quanto manutenção (Atkinson et al., 2015; Credeur et al., 2010) da taxa de cisalhamento retrógrado durante o exercício.

Diferentes protocolos de exercício apresentam variações na velocidade e padrão de fluxo sanguíneo, que acarretam nos diferentes efeitos agudos e sub- 
agudos do exercício na função endotelial demonstrados na literatura. Estudos que utilizaram protocolos com bicicleta ergométrica demonstraram que durante a realização do exercício ocorre um aumento significativo de todos os componentes do fluxo sanguíneo, ou seja, taxas de cisalhamento média, anterógrada e retrógrada (Padilla et al., 2011b). Já em protocolos de preensão manual é possível verificar aumentos significativos na taxas de cisalhamento média e anterógrada, enquanto o comportamento da taxa de cisalhamento retrógrada é controverso, podendo ocorrer manutenção (Atkinson et al., 2015; Credeur et al., 2010) ou elevação desse componente (Tinken et al., 2009; Tinken et al., 2010). A diferença no padrão de fluxo em uma mesma modalidade pode ser explicada pelas diferentes intensidades de exercício empregada nos estudos, sendo que está variável está associada também a resposta aguda da função endotelial em protocolos de preensão manual (Atkinson et al., 2015); cabe ressaltar que não foi verificada esta associação entre intensidade e resposta aguda da FMD em exercícios de esteira (Harris et al., 2008; Johnson et al., 2012). A cadência de realização do exercício também pode alterar o padrão de fluxo, no entanto essa mudança não é acompanhada de diferenças na resposta da FMD desde que a taxa de cisalhamento média permaneça igual (King et al., 2013). A duração do exercício parece não influenciar a resposta aguda (Johnson et al., 2012). É interessante destacar que as taxas de cisalhamento podem variar durante a realização do exercício (Padilla et al., 2011b).

Diferenças nas populações estudadas também podem alterar os resultados encontrados, Harvey et al. (2005) conduziram um estudo comparando a resposta aguda a um protocolo de esteira de mulheres pós-menopausadas em relação a mulheres pré-menopausadas, e reportaram uma diferença significativa tanto na FMD de repouso entre os dois grupos quanto na magnitude de aumento dessa variável após o exercício. Os autores propuseram que existe uma correlação negativa entre o estado inicial (FMD de repouso) e a melhora na função endotelial associada a atividade física. O nível de atividade física, independente de diferenças na FMD de repouso, também afeta a resposta da função endotelial ao exercício. Harris et al. (2008) reportaram aumento nos valores de FMD de sujeitos obesos ativos em resposta a um protocolo de esteira, ao passo que sujeitos obesos inativos tiveram redução nos valores de FMD. Indivíduos idosos também apresentam alterações na 
resposta aguda, demonstrando menor FMD de repouso quando comparados com indivíduos jovens e também sendo proposto que essa população apresenta células endoteliais menos responsivas ao estresse de cisalhamento (Schreuder et al., 2015).

Além de respostas agudas e sub-agudas nos valores de FMD, uma única sessão de exercício físico pode induzir alterações em outras variáveis associadas a função endotelial, como $A U_{S R}$, fluxo sanguíneo e concentrações substâncias vasoativas circulantes. Já foram reportados na literatura aumentos da reatividade vascular, capacidade vasodilatadora e fluxo sanguíneo durante a hiperemia por até 60 minutos após protocolos máximos de exercício (Baynard et al., 2003; BousquetSantos et al., 2005). Harvey et al. (2005) demonstraram aumento na condutância vascular periférica após uma única sessão de treinamento na esteira, correlacionada positivamente com o aumento observada na FMD. Os efeitos do exercício sobre a $\mathrm{AUC}_{\mathrm{SR}}$ são controversos, com estudos reportando aumento (Atkinson et al., 2015; Johnson et al., 2012) ou manutenção (Harris et al., 2008; Schreuder et al., 2014; Thijssen et al., 2009; Tinken et al., 2009) dos valores desta variável Alterações no estresse oxidativo e citosinas inflamatórias (IL-6) também já foram reportadas após o exercício, no entanto não foi verificada associação entre essas alterações e as variações nos valores de FMD (Harris et al., 2008; Johnson et al., 2012). Cabe ressaltar que a vasodilatação independente do endotélio por meio da administração de gliceril trinitato não apresenta diferenças após a prática de atividades físicas (Harvey et al., 2005; Tinken et al., 2009).

\subsubsection{Oclusão vascular e função endotelial}

O método de oclusão vascular, também conhecido como Kaatsu Training, é um método de treinamento que se baseia na utilização de um manguito insuflado posicionado no membro que está sendo exercitado com o objetivo de causar restrição do fluxo sanguíneo (BFR) e redução do retorno venoso, promovendo ganhos de massa e força muscular de magnitude comparável, ou maior, do que o treinamento tradicional (Fry et al., 2010; Takarada et al., 2000). Entretanto o treinamento combinado com este método aparenta ser prejudicial para a função endotelial. De maneira crônica foi verificado que a oclusão vascular pode atenuar ou 
até abolir as adaptações decorrentes do exercício resultando na manutenção dos valores de FMD após um período de treinamento, ao passo que o indivíduos que realizaram o mesmo protocolo sem a utilização do método demonstraram aumentos significativos (Tinken et al., 2010). Credeur et al. (2010) verificaram uma redução de aproximadamente $30 \%$ na FMD após 4 semanas de treinamento de preensão manual combinado com a BFR, enquanto o braço controle obteve aumento de cerca de $24 \%$. Os efeitos agudos e sub-agudos do exercício também são alterados com a utilização da oclusão vascular. O aumento da FMD encontrado logo após uma sessão de exercício é atenuado, podendo até ocorrer uma redução dos valores de FMD em relação aos valores inicias (Tinken et al., 2009; Tinken et al., 2010).

Os prejuízos crônicos e agudos encontrados pela utilização da oclusão vascular são atribuídos principalmente a alterações agudas no padrão de fluxo sanguíneo decorrentes da utilização do manguito (Figura 4). Durante o repouso a insuflação do manguito pode promover redução da taxa de cisalhamento anterógrada (Credeur et al., 2010) e também aumento dose-dependente da taxa de cisalhamento retrógrada (Schreuder et al., 2014; Thijssen et al., 2009), sendo necessário ressaltar que a magnitude de aumento no fluxo retrógrado encontrados nestes estudos foi correlacionado inversamente com a resposta aguda da FMD. Durante o exercício a utilização do método atenua ou impede o aumento de todos os componentes do fluxo sanguíneo (Naylor et al., 2011; Tinken et al., 2009; Tinken et al., 2010), sendo que a redução das taxas de cisalhamento anterógrada e média durante o exercício pode prejudicar os efeitos agudos e crônicos do exercício na função endotelial (Naylor et al., 2011; Tinken et al., 2010). Adicionalmente a BFR pode induzir maiores respostas hemodinâmicas durante a realização do exercício, conforme verificado por maior aumento na frequência cardíaca, pressão arterial sistólica e diastólica em relação a uma sessão de exercício tradicional (Vieira et al., 2013).

Além de efeitos negativos na função endotelial o treinamento com restrição do fluxo venoso pode interferir nas adaptações estruturais e remodelamento vascular que ocorre após longos períodos de treinamento, no entanto a literatura apresenta dados controversos. Hunt et al. (2012) verificam aumentos no diâmetro pico, fluxo hiperêmico e capacidade de dilatação em reposta ao exercício isquêmico, indicativos de remodelamento vascular, após 4 semanas de treinamento somente no braço que 
utilizou o método, enquanto o braço controle não apresentou diferenças, já Tinken et al. (2010) encontrou resultados contrários, demonstrando aumentos somente para o braço controle.

FIGURA 4 - Padrão de fluxo sanguíneo em repouso (A), durante restrição do fluxo sanguíneo (B) e hiperemia reativa (C).
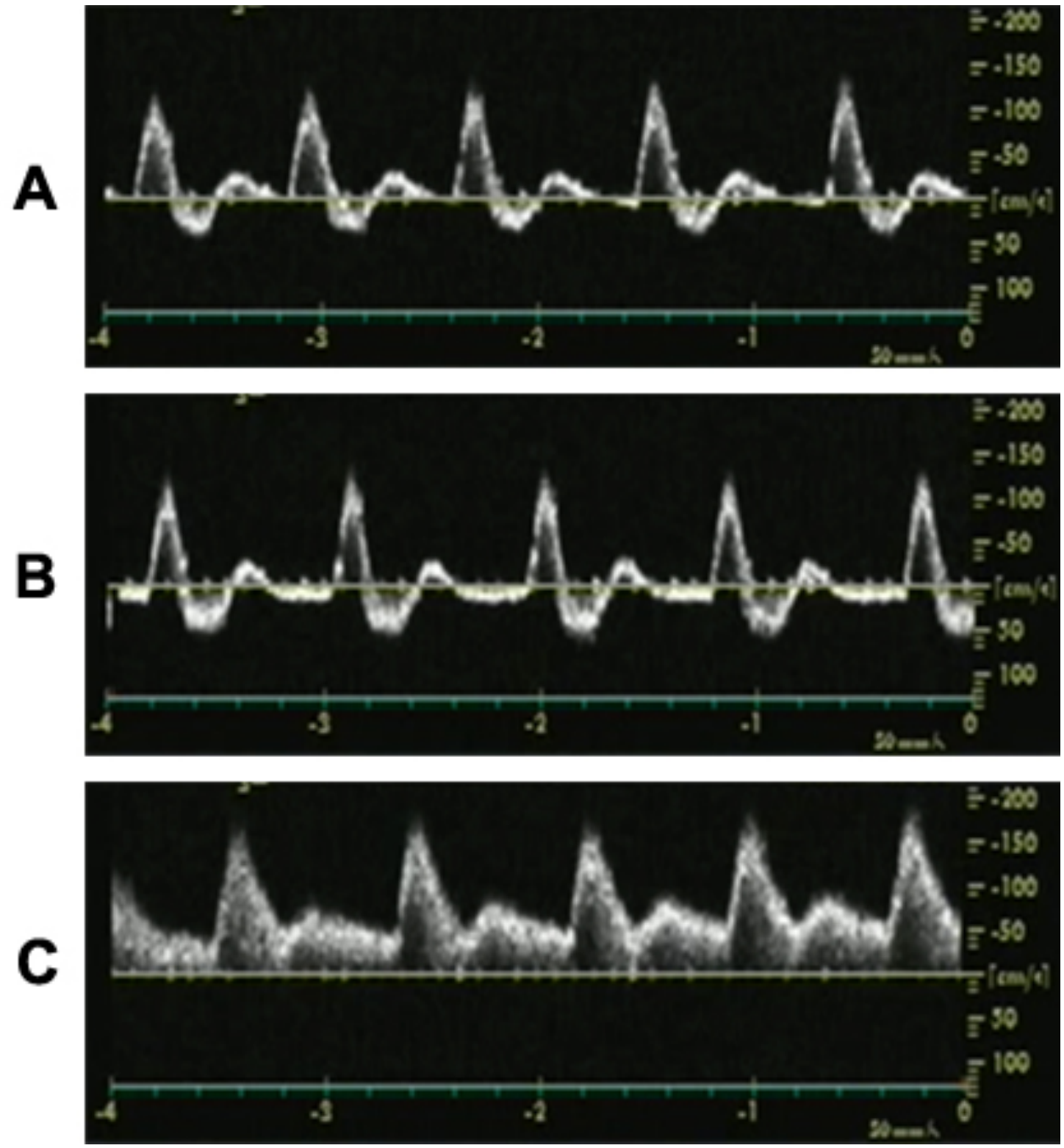


\section{MATERIAL E MÉTODOS}

\subsection{Amostra}

Nove homens saudáveis (média \pm erro padrão: idade $=28 \pm 1.8$ ) dos corpos estudantis da Universidade Federal Fluminense e da Universidade de Brasília foram selecionados para participar do estudo. Foram considerados como critérios de exclusão o diagnóstico ou evidência de qualquer doença cardiovascular, metabólica, ortopédica, neurológica ou endócrina que sabidamente afetem a função endotelial; uso de qualquer medicação que possa interferir coma a função cardiovascular; tabagismo; e risco de respostas adversas ao exercício.

\subsection{Cuidados éticos}

A participação no estudo foi realizada de maneira voluntária e mediante a assinatura do Termo de Consentimento Livre e Esclarecido (Anexo A), o qual contem informações acerca dos métodos utilizados, possíveis riscos e benefícios. Os voluntários também permitiram, mediante a assinatura do termo supracitado, a utilização dos dados coletados para finalidades de pesquisa e publicação científica, sendo resguardada a identidade dos participantes em todos os momentos.

Todos os protocolos utilizados no presente projeto foram aprovados pelo Comitê de Ética em Pesquisa da Universidade Federal Fluminense (CAAE: 09282812.3.0000.5243) e estão de acordo com a Resolução no 196/96 do Conselho Nacional de Saúde (CNS) que regulamenta as pesquisas envolvendo seres humanos.

\subsection{Desenho experimental}

O estudo teve caráter experimental e analisou as seguintes variáveis dependentes: dilatação fluxo mediada, velocidade e padrão de fluxo sanguíneo. A variável independente foi o protocolo de exercício de preensão manual, combinado 
ou não com a BFR. Duas variáveis intervenientes foram utilizadas visando manter a homogeneidade da amostra: idade (18 a 40 anos) e sexo (masculino).

Todas as coletas foram realizadas no campus da Universidade Federal Fluminense no Laboratório de Ciências do Exercício (LACE). Os sujeitos compareceram ao laboratório somente uma vez por um período aproximado de 2 horas, no qual foram realizados todos os procedimentos experimentais (Figura 5). Todos os sujeitos foram instruídos a ficar de jejum e se abster do consumo de cafeína, tabaco, álcool e da realização de atividades físicas por no mínimo 12 horas antes do experimento.

Inicialmente a FMD e o padrão de cisalhamento do fluxo sanguíneo foram mensurados bilateralmente depois de no mínimo 20 minutos de repouso na posição supina em uma sala silenciosa e com temperatura controlada, em seguida um protocolo de 20 minutos de exercício de preensão manual foi realizado e a FMD foi reavaliada 15 e 60 minutos após o término do exercício. Adicionalmente, um manguito posicionado em um dos braços do sujeito (braço experimental - EXP) foi insuflado a $80 \mathrm{mmHg}$ durante toda a duração do exercício para induzir alterações no padrão de fluxo sanguíneo. A velocidade e padrão de fluxo sanguíneo também foram mensurados imediatamente antes do início e durante a realização do exercício.

Figura 5 - Procedimentos experimentais.

\begin{tabular}{|c|c|c|c|c|c|c|c|}
\hline $\begin{array}{c}20 \mathrm{~min} \\
\text { repouso }\end{array}$ & $\begin{array}{c}\text { FMD } \\
\text { (Repouso) }\end{array}$ & Fluxo Pré & $\begin{array}{c}\text { Exercicio } \\
+\end{array}$ & $\begin{array}{c}15 \mathrm{~min} \\
\text { Fluxo Durante }\end{array}$ & $\begin{array}{c}\text { FMD } \\
\text { repouso }\end{array}$ & $\begin{array}{c}\sim 40 \mathrm{~min} \\
\text { repouso }\end{array}$ & $\begin{array}{c}\text { FMD } \\
(60 \mathrm{~min})\end{array}$ \\
\hline
\end{tabular}

\subsection{Força de preensão manual}

Para determinação da força de preensão manual os sujeitos realizaram três contrações isométricas voluntárias máximas (MVC) com cada braço. Dois dinamômetros digitais (MLT004/S, ADInstruments, Nova Zelândia) conectados a um sistema de aquisição de dados (PowerLab, ADInstruments, Nova Zelândia) foram utilizados para avaliação da força de preensão manual. Todas as avaliações foram 
realizadas com os sujeitos deitados em uma maca na posição supina, os braços ficaram posicionados ao lado do corpo e os cotovelos estavam completamente estendidos. Os sujeitos foram instruídos a realizar o máximo de força possível durante 3 segundos, repetindo esse procedimento três vezes para cada braço com 1 minuto de intervalo entre as tentativas. $O$ braço esquerdo foi avaliado primeiro em todos os sujeitos. A análise dos dados obtidos foi realizada no software LabChart (ADInstruments, Nova Zelândia), demonstrado na Figura 6, e a mediana das três medidas de cada braço foi considerada como a MVC.

FIGURA 6 - Software utilizado para mensuração da MVC.

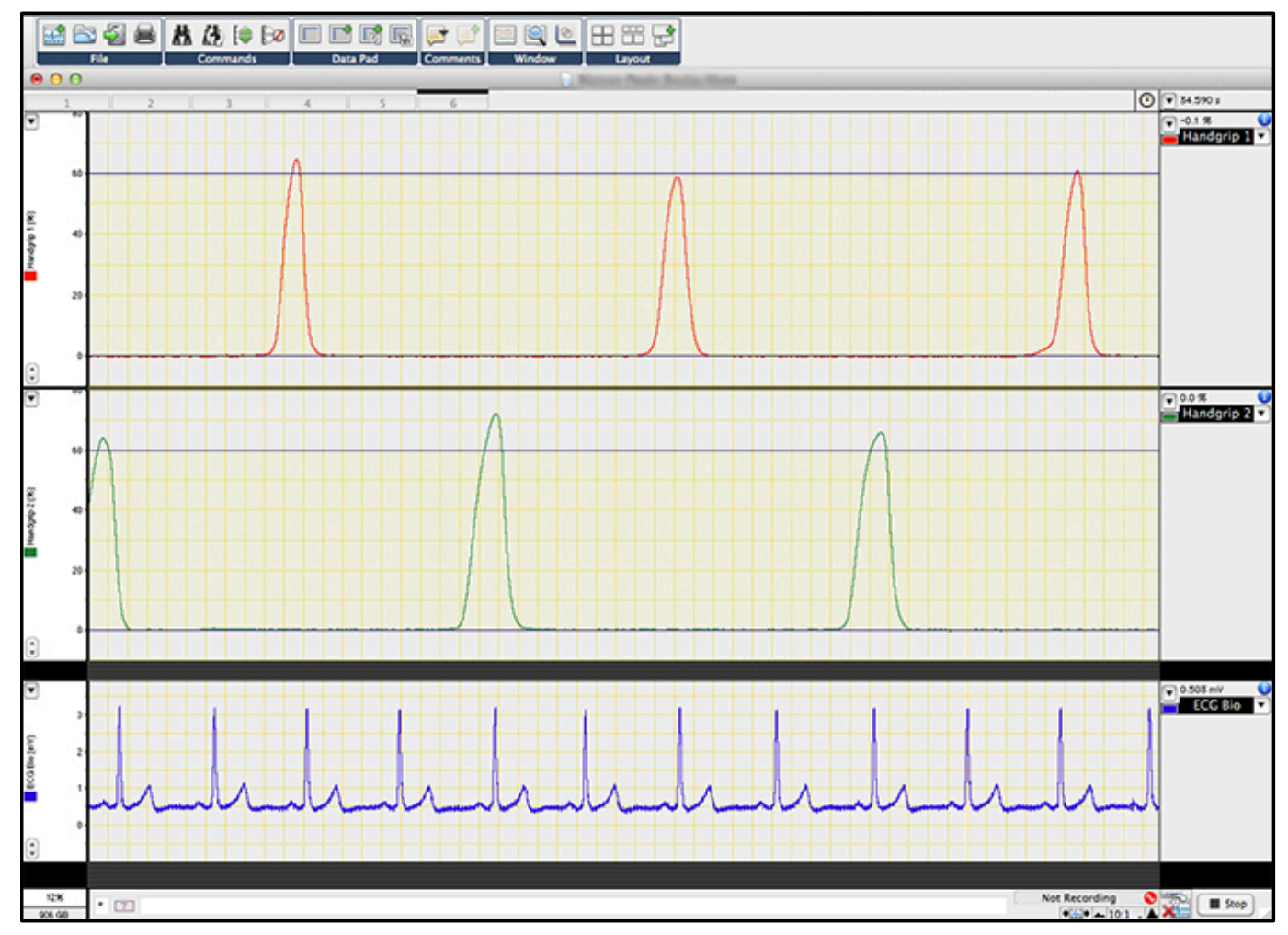

\subsection{Dilatação fluxo-mediada e velocidade do fluxo sanguíneo}

As imagens bilaterais da artéria braquial foram realizadas por meio de ultrassonografia com Doppler (LOGIC P5 e VIVID 7, GE Healthcare, Reino Unido), utilizando transdutores de arranjo linear atuando em 10 e $5 \mathrm{MHz}$ para análise do diâmetro arterial e velocidade de fluxo sanguíneo, respectivamente. Os transdutores foram posicionados a aproximadamente $2 \mathrm{~cm}$ proximal da fossa antecubital e as 
imagens foram obtidas no plano longitudinal, as configurações de ganho dos ultrassons foram ajustadas de modo a otimizar a visualização das paredes da artéria braquial. A velocidade do fluxo sanguíneo por meio de Doppler pulsado foi coletada simultaneamente com o diâmetro em modo Duplex, o sinal foi pulsado em um ângulo corrigido de $60^{\circ}$ em relação ao vaso, com o cursor posicionado no centro da artéria e com a maior área de amostragem possível. Todas as imagens e procedimentos de avaliação estão de acordo com as instruções da International Brachial Artery Reactivity Task Force, levando também em consideração as atualizações propostas na literatura (Corretti et al., 2002; Harris et al., 2010).

A oclusão vascular no antebraço foi realizada por meio de manguitos posicionados em ambos os braços a aproximadamente $2 \mathrm{~cm}$ distal da fossa antecubital, os manguitos foram rapidamente insuflados a $250 \mathrm{mmHg}$ por meio de um aparelho E20 Rapid Cuff Inflator (D.E. Hokanson, Estados Unidos da América) e permaneceram com esta pressão durante 5 minutos. Imagens para análise do diâmetro arterial e velocidade de fluxo sanguíneo foram obtidas por 1 minuto durante o repouso e continuamente dos últimos 30 segundos de oclusão até 2 minutos após a liberação dos manguitos. Todas as imagens foram capturadas por meio de uma placa de captura de vídeo USB (Easy Cap, Leadership, Brasil) na frequência de 30 $\mathrm{Hz}$ e salvas em disco rígido externo para posterior análise. A frequência cardíaca foi monitorada durante todo o experimento por meio de eletrocardiograma de três derivações.

Um subgrupo de 7 sujeitos foi submetido a análise do padrão de fluxo sanguíneo imediatamente antes e durante a realização do exercício de preensão manual (Figura 7), em ambos os momentos o manguito posicionado do braço EXP estava insuflado a $80 \mathrm{mmHg}$. O propósito dessa análise adicional foi verificar os efeitos da restrições do fluxo sanguíneo e do exercício no padrão de cisalhamento. Os transdutores foram posicionados no mesmo local mencionado anteriormente e imagens foram gravadas bilateralmente durante 1 minuto, os arquivos foram salvos em disco rígido externo para posterior análise. 


\subsection{Análise dos dados}

O software semiautomático FMD Studio (Institute of Clinical Physiology, Itália) foi utilizado para as análises de diâmetro arterial e velocidade de fluxo sanguíneo, a reprodutibilidade desse software foi previamente demonstrada com um coeficiente de variação intra-sessão de $9.9 \pm 8.4 \%$ (Ghiadoni et al., 2012). Após delimitação da região de interesse na imagem obtida pelo ultrassom, o software realizava a detecção automática das paredes da artéria e calculava o diâmetro arterial como sendo a distância entre elas. $O$ diâmetro inicial foi definido como a média de 1 minuto de dados obtidos antes do manguito ser insuflado, já o diâmetro pico foi definido como o maior valor de diâmetro encontrado após a liberação do manguito. A FMD da artéria braquial foi calculada como a diferença percentual entre o diâmetro inicial e o diâmetro pico.

FIGURA 7 - Avaliação bilateral do padrão de fluxo sanguíneo durante a realização do exercício de preensão manual.

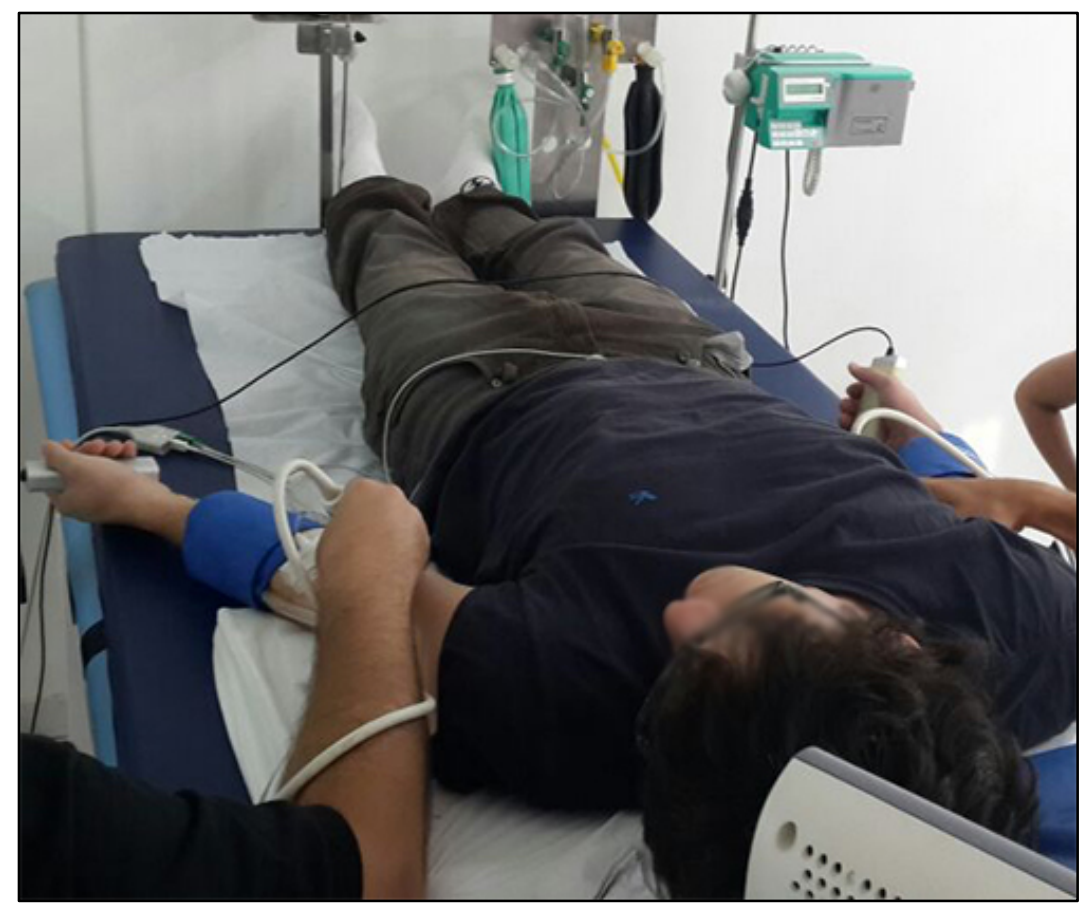

Os componentes anterógrado e retrógrado do fluxo sanguíneo foram definidos como a área cima e abaixo do $0 \mathrm{~cm} \cdot \mathrm{s}^{-1}$ no eixo horizontal do Doppler, 
respectivamente. Os dados foram apresentados pelo software como taxa de cisalhamento anterógrado $\left(\mathrm{SR}_{\mathrm{ANT}}\right)$ e taxa de cisalhamento retrógrada $\left(\mathrm{SR}_{\mathrm{RET}}\right)$. $\mathrm{A}$ taxa de cisalhamento média $\left(\mathrm{SR}_{\mathrm{MEAN}}\right)$ foi calculada como a diferença entre os componentes anterógrado e retrógrado. A área sob a curva da taxa de cisalhamento $\left(A \cup C_{S R}\right)$, indicativo do estímulo para vasodilatação, foi calculada do momento da liberação do manguito até o diâmetro de pico ser atingido. O fluxo sanguíneo foi calculado a partir da fórmula Fluxo $=V_{m} \pi\left(D^{2} / 4\right) \times 60$, na qual $V m$ corresponde a velocidade média do fluxo sanguíneo em centímetros por segundo e $D$ representa o diâmetro da artéria braquial em centímetros (Pennati et al., 1998); a velocidade média por sua vez foi obtida pela fórmula $\mathrm{Vm}=\left(\mathrm{SR}_{\mathrm{MEAN}} \times \mathrm{D}\right) \div 4$. O índice de oscilação do fluxo foi determinado como $S R_{R E T} /\left(S R_{A N T}+S R_{R E T}\right)$ (Padilla et al., 2011b), sendo que os valores obtidos variam de 0 a 0,5 indicando fluxo laminar unidirecional e pura oscilação, respectivamente.

FIGURA 8 - Imagem da artéria braquial gerada pelo ultrassom e utilizada para análises de diâmetro arterial e velocidade de fluxo.

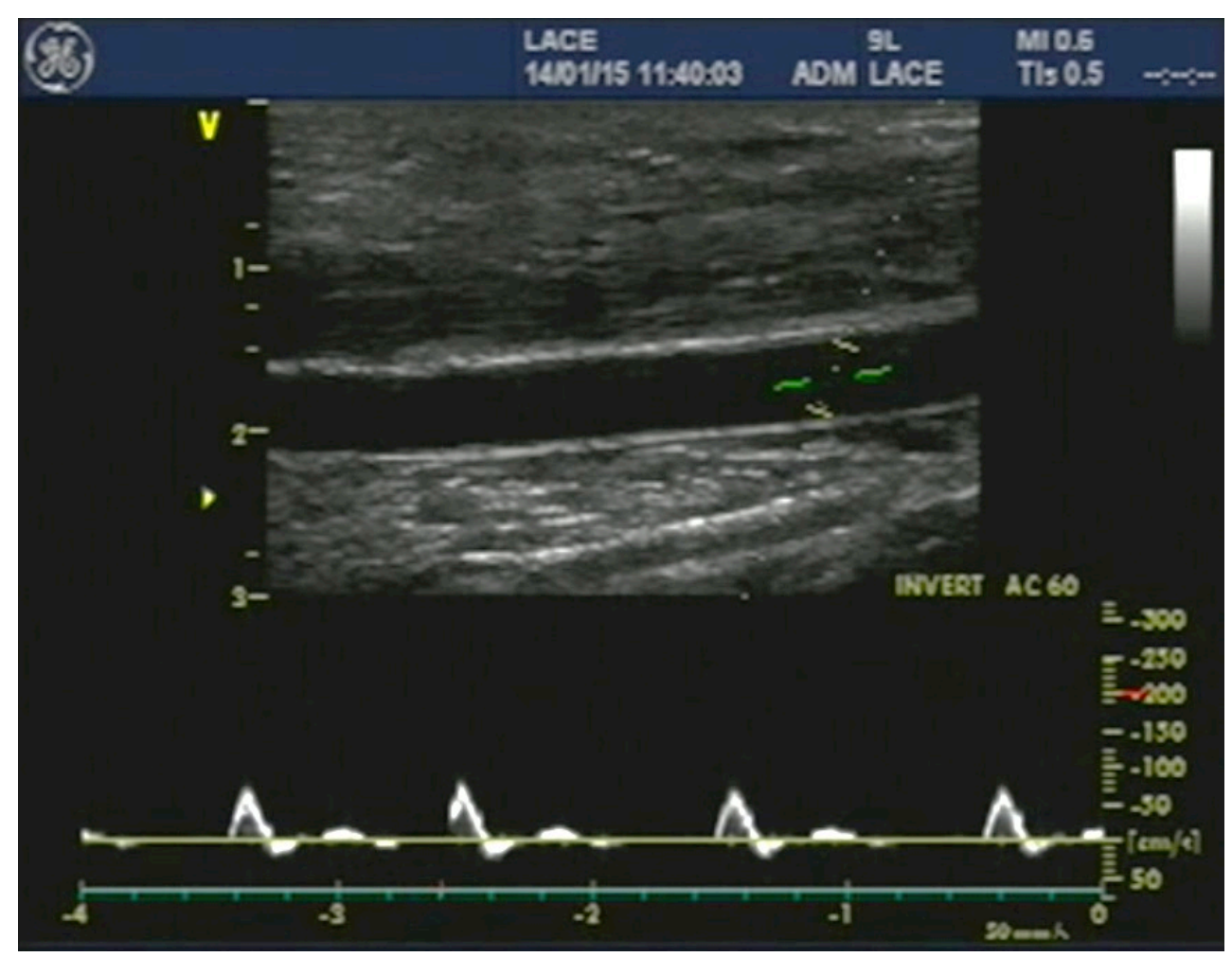




\subsection{Protocolo de exercício}

A sessão de exercício teve duração de 20 minutos e consistiu na realização de preensão manual bilateral com intensidade de $60 \%$ da MVC. O exercício foi realizado de maneira alternada entre os braços no ritmo de 1 contração a cada 4 segundos, em um total de 15 contrações por minuto. Um metrônomo digital a 60 bpm foi utilizado para auxiliar os sujeitos na manutenção do ritmo. O exercício foi realizado com os sujeitos deitados sobre uma maca na posição supina, com os braços posicionados ao lado do corpo e cotovelos estendidos, foi fornecido um feedback visual para os voluntários para assegurar que a intensidade do exercício fosse mantida durante toda a duração do protocolo. Um intervalo opcional de 1 minuto era permitido após os primeiros 10 minutos de exercício, o tempo de intervalo não contou para a duração total do exercício de 20 minutos. A percepção subjetiva de esforço (PSE) foi coletada nos minutos 10 e 20 do protocolo por meio de uma escala de Borg adaptada de 0 a 10.

No braço EXP, selecionado de maneira aleatória para todos os sujeitos, o manguito previamente posicionado no antebraço foi insuflado a $80 \mathrm{mmHg}$ antes do início do exercício e mantido durante toda a sessão, com o objetivo de alterar o padrão de fluxo sanguíneo. $O$ manguito no braço controle (CON) permaneceu a 0 $\mathrm{mmHg}$ durante todo o protocolo de exercício. Foi previamente demonstrado na literatura que a utilização do manguito insuflado a $80 \mathrm{mmHg}$ em um braço não altera a velocidade de fluxo sanguíneo, o padrão de fluxo sanguíneo ou a FMD no braço contralateral (Thijssen et al., 2010).

O presente protocolo está de acordo com o proposto na literatura para promover efeitos crônicos (Credeur et al., 2010; Dobrosielski et al., 2009) e agudos (Atkinson et al., 2015; Tinken et al., 2009; Tinken et al., 2010) na função endotelial.

\subsection{Análise estatística}

O software Statistical Package for Social Sciences versão 22.0 (SPSS Inc., Estados Unidos da América) foi utilizado para realização de todos os procedimentos estatísticos. O teste de Shapiro-Wilk foi utilizado para verificar a normalidade de 
distribuição dos dados. Para verificar os efeitos sub-agudos do exercício de preensão manual na função endotelial foi realizada uma análise de variância (ANOVA) de medidas repetidas 2 (braço EXP e braço CON) x 3 (Repouso, 15 e 60 minutos após). ANOVAs subsequentes foram realizadas para avaliar os efeitos sub-agudos do exercício no diâmetro da artéria braquial, tempo até o pico de dilatação, $A_{U} C_{S R}$ e fluxo sanguíneo. Diferenças entre as médias foram avaliadas por meio de um teste post-hoc LSD. Testes $T$ pareados foram utilizados para verificar diferenças entre as taxas de cisalhamento dos braços CON e EXP durante o repouso e o exercício de preensão manual. Foi utilizada a correlação de Pearson para verificar a relação entre as taxas de cisalhamento durante o exercício e a alteração na FMD ( $\triangle F M D)$ nos minutos 15 e 60, bem como a relação entre o índice de oscilação do fluxo e $\triangle F M D$. Todos os dados estão expostos como média \pm erro padrão. O nível de significância estatística adotado foi de $\mathrm{P} \leq 0,05$. 


\section{RESULTADOS}

As características iniciais dos sujeitos estão apresentadas na tabela 1. Nenhum indivíduo reportou o diagnóstico de doenças ou a utilização de medicamentos que afetem o sistema cardiovascular. Todos os sujeitos completaram o protocolo de exercício, a PSE relatada pelos sujeitos foi de 4,56 $\pm 0,65$ para o minuto 10 e $5,38 \pm 0,53$ para o minuto 20 .

TABELA 1 - Caracterização da amostra $(n=9)$.

\begin{tabular}{lccc}
\hline & Média & & $\mathrm{DP}$ \\
\hline Idade (anos) & 27 & \pm & 5,8 \\
Altura (cm) & 180 & \pm & 6,9 \\
Massa Corporal $(\mathrm{kg})$ & 81 & \pm & 8,1 \\
IMC (kg/m ${ }^{2}$ ) & 25 & \pm & 2,6 \\
MVC Direito (N) & 497 & \pm & 102,3 \\
MVC Esquerdo (N) & 481 & \pm & 111,1 \\
\hline
\end{tabular}

Valores apresentados como média \pm desvio padrão.

Valores relativos a diâmetro arterial, tempo até o pico de dilatação, $A_{U} C_{S R}$ e fluxo sanguíneo estão expostos na tabela 2. Resultados da ANOVA 2x3 não demonstram interação significativa para o $A_{S R}(P=0,93)$, no entanto existiu um efeito de tempo significativo ( $P \leq 0,01)$; a análise post-hoc demonstrou maiores valores de $A \cup C_{S R} 15$ minutos após o término do exercício para os braços CON $(P=$ $0,01)$ e $\operatorname{EXP}(P=0,03)$ quando comparados com o repouso. Similarmente, não existiu interação significativa para o diâmetro de pico $(P=0,60)$, no entanto existiu um fator de tempo significativo somente para o braço CON nos momentos 15 e 60 minutos após o exercício ( $P=0,01$ para ambos). Não existiu interação significativa para o diâmetro de repouso $(P=0,13)$ e tempo até o pico de dilatação $(P=0,511)$, também não foram encontrado efeitos significativos de condição $(P=0,06$ e $P=$ $0,97$ ) ou tempo ( $P=0,16$ e $P=0,28)$. Não existiu interação significativa para o fluxo sanguíneo $(P=0,19)$, no entanto existiu um efeito significativo de condição $(P=0,04)$ com a análise post-hoc demonstrando fluxo sanguíneo elevado no braço EXP 15 minutos após o exercício quando comparado com o braço CON no mesmo momento. 
TABELA 2 - Diâmetro da artéria braquial, tempo até o pico de dilatação, $A U C_{S R}$ e fluxo sanguíneo no repouso e após a sessão de exercício.

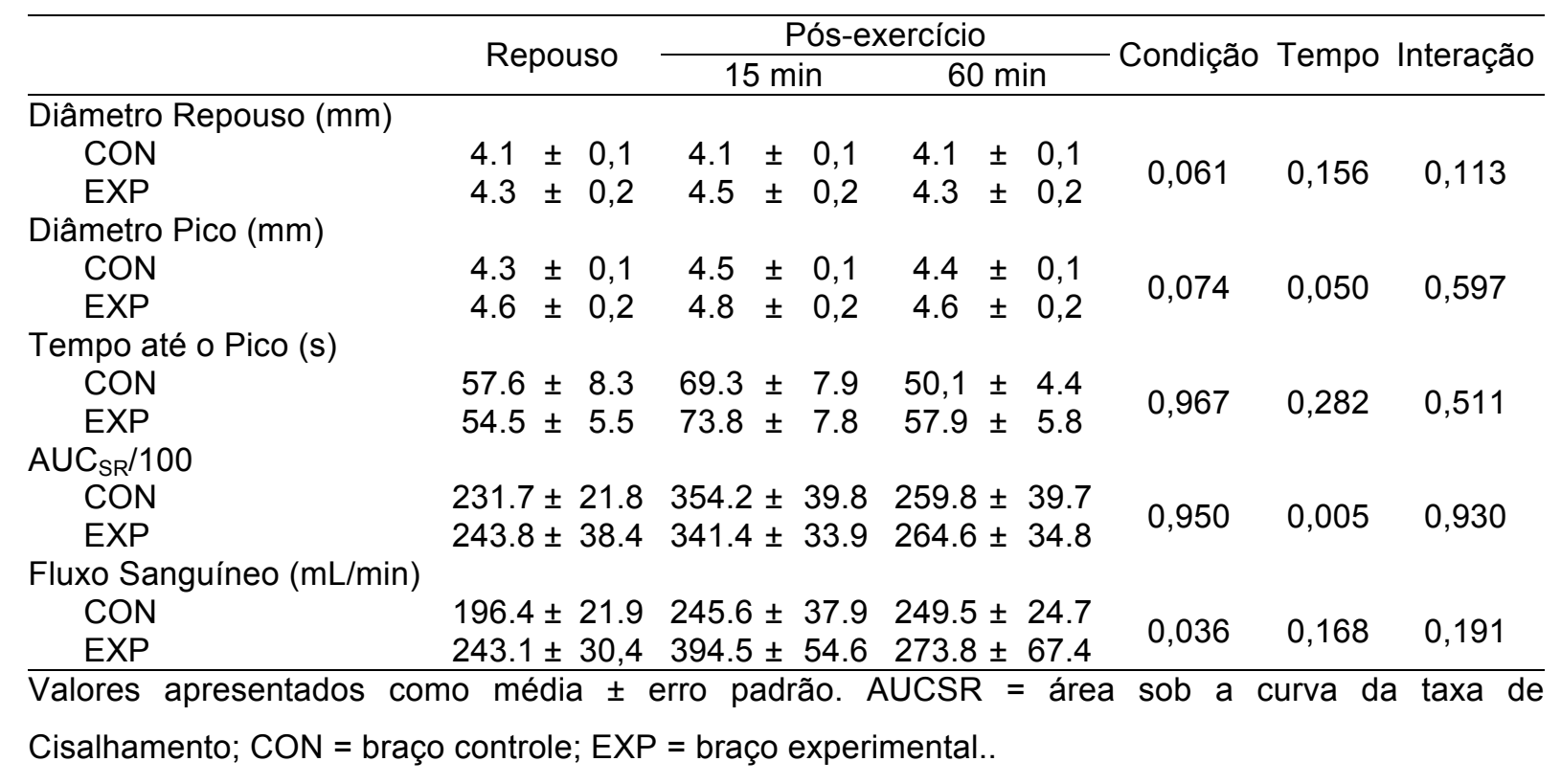

Os resultados da ANOVA 2x3 relativa a FMD estão apresentados na Figura 9. Não foram encontradas diferenças entre a FMD no momento inicial entre os dois braços (CON $=5,98 \pm 0,56 \%$ e EXP $=6,04 \pm 0,63 \%)$. Foi verificara uma interação significativa para FMD $(P=0,01)$, a análise post-hoc demonstrou $F M D$ aumentada 15 minutos após o exercício para o braço $\operatorname{CON}(64,09 \pm 16,59 \%, P \leq 0,01$, mudança absoluta de $0,13 \mathrm{~mm})$, enquanto não houve alteração no braço $\operatorname{EXP}(-12,41 \% \pm$ $12,64, P=0,25$, mudança absoluta de $-0,01 \mathrm{~mm}$ ); também foi encontrada uma diferença significativa entre ambos os braços nesse momento $(P \leq 0,01)$. Os valores de FMD não foram significativamente diferentes dos iniciais no momento 60 minutos após o exercício (CON: $P=0,08$ e EXP: $P=0,08$ ), também não foi verificada diferença significativa entre os dois braços no minuto $60(P=0,42)$.

$\mathrm{O}$ índice de oscilação do fluxo, apresentado na figura 10 , foi significativamente maior para o braço EXP tanto em repouso após insuflar o manguito $(P=0,03)$ quando durante o exercício $(P=0,01)$, os valores do braço EXP reduziram significativamente durante o exercício em relação os valores do repouso $(P \leq 0,01)$. 
FIGURA 9 - FMD no repouso e após (15 e 60 minutos) o protocolo de preensão manual para os braços CON e EXP.

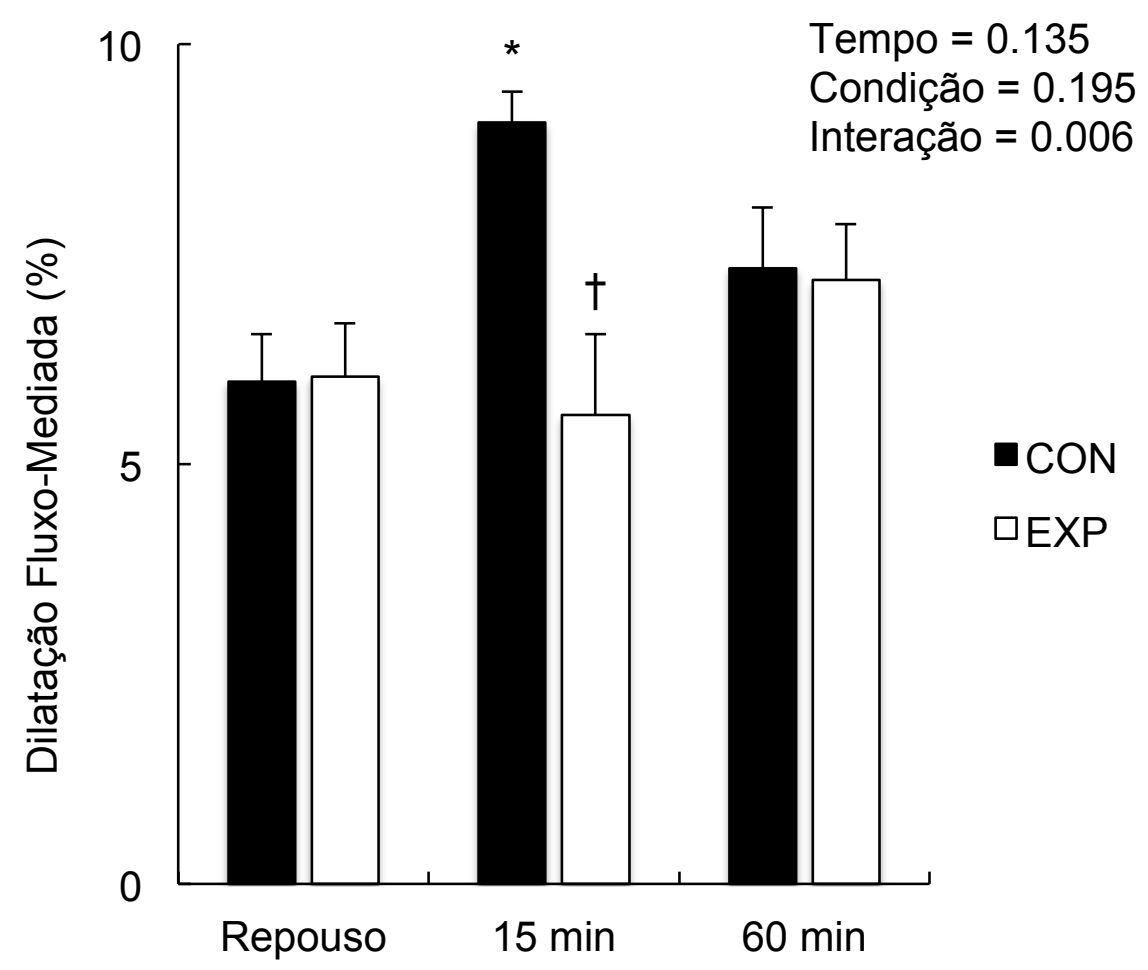

${ }^{*} P \leq 0,01$ em relação ao mesmo braço no repouso, $\dagger P \leq 0,01$ em relação ao braço $C O N$ no mesmo momento.

A Figura 11 apresenta os resultados da análise do padrão de cisalhamento. Existiu um aumento significativo na taxa de cisalhamento retrógrada devido a insuflação do manguito no braço EXP (pré-insuflação $=-28,99 \pm 11,69 \mathrm{~s}^{-1}$; pósinsuflação $\left.=-153,18 \pm 30,82 \mathrm{~s}^{-1} ; \mathrm{P} \leq 0,01\right)$, consequentemente o componente retrógrado estava significativamente maior no braço EXP do que no braço CON antes do início do exercício $\left(C O N=-42,05 \pm 9,61 \mathrm{~s}^{-1}\right.$ e EXP $=-153,18 \pm 30,82 \mathrm{~s}^{-1} ; \mathrm{P}$ $=0,01)$. Também existiu uma diferença significativa na taxa de cisalhamento média em repouso entre os dois braços $(\mathrm{CON}=126,82 \pm 26,27$ s-1 e EXP $=26,80 \pm 23,81$ $\mathrm{s}-1 ; \mathrm{P}=0,02)$. Tanto o aumento na taxa de cisalhamento retrógrada quanto na média permaneceram significativamente maiores no braço EXP durante o protocolo de exercício ( $P=0,04$ e $P=0,03$, respectivamente). As taxas de cisalhamento anterógrada e retrógrada durante o exercício foram significativamente maiores em relação ao responso nos braços $\operatorname{CON}(P \leq 0,01)$ e EXP $(P \leq 0,01)$, no entanto não 
ocorreu aumento significativo na taxa de cisalhamento retrógrada $(P=0,41$ e $P=$ $0,10)$.

FIGURA 10 - Índice de oscilação do fluxo em repouso e durante exercício de preensão manual para os braços CON e EXP.

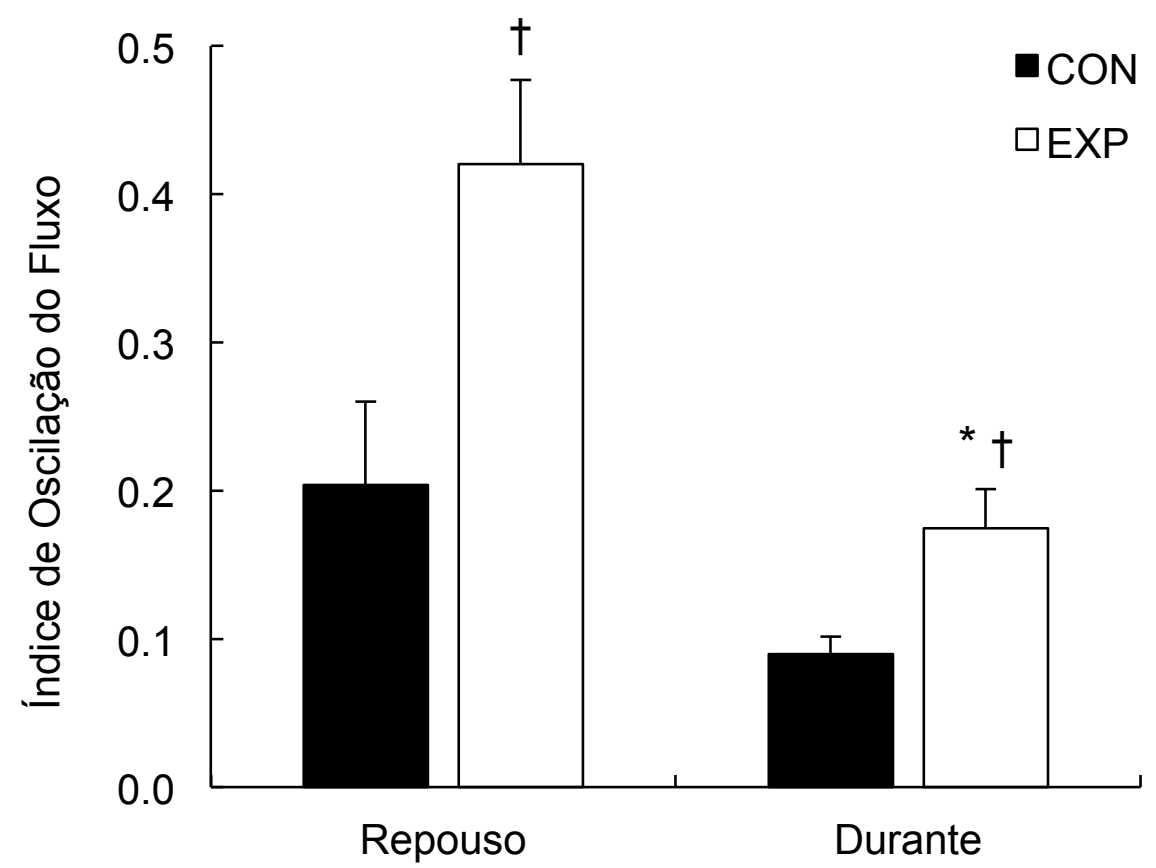

${ }^{*} P \leq 0,01$ em relação ao mesmo braço no repouso, $\dagger P \leq 0,01$ em relação ao braço $C O N$ no mesmo momento. 
FIGURA 11 - Taxas de cisalhamento (média, anterógrada e retrógrada) no repouso e durante o exercício de preensão manual para os braços CON e EXP.
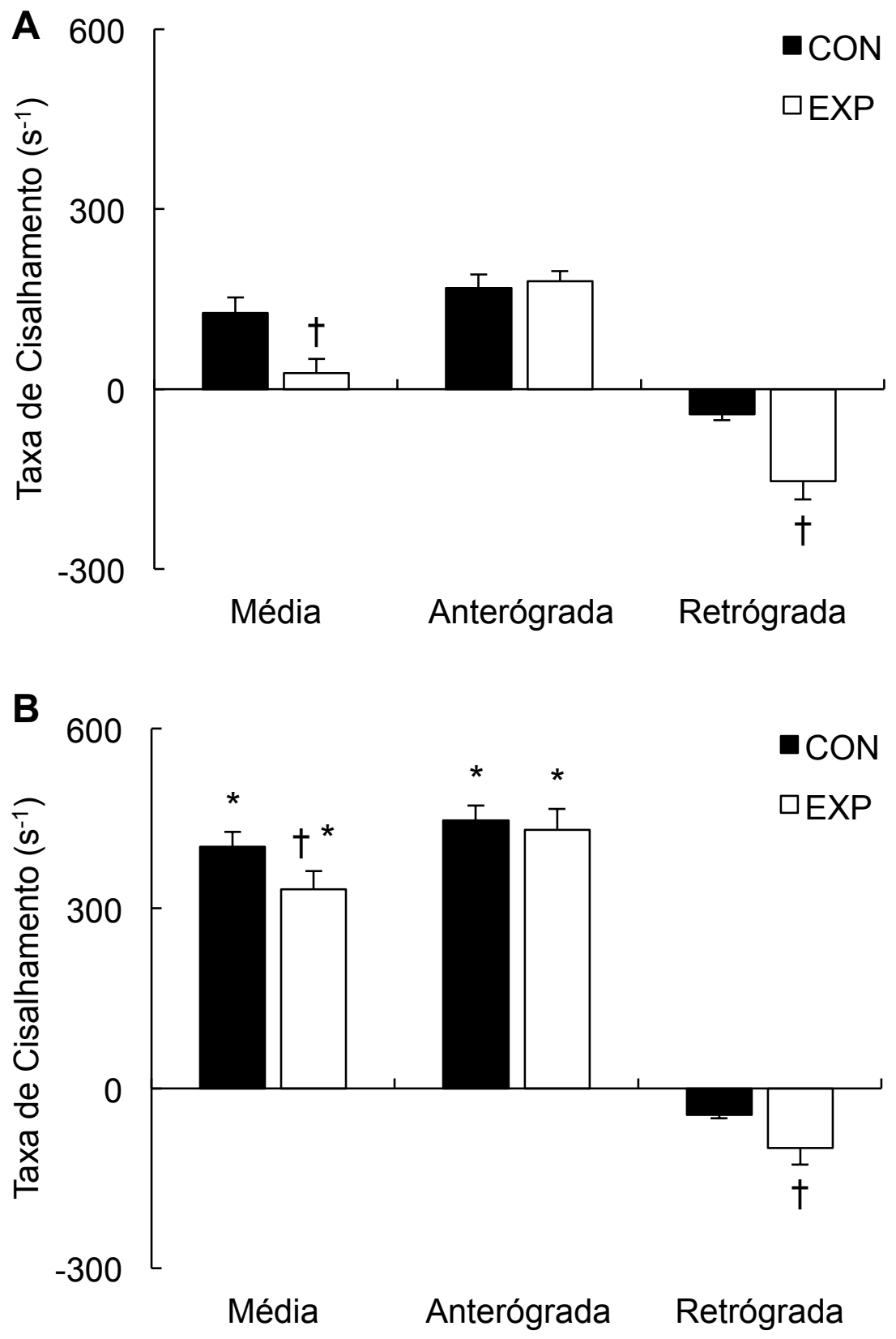

A. Repouso com manguito insuflado a $80 \mathrm{mmHg}$ no braço EXP. B. Durante exercício com manguito insuflado a $80 \mathrm{mmHg}$ no braço EXP. ${ }^{*} P \leq 0,01$ em relação ao mesmo braço no repouso, $† P \leq 0,01$ em relação ao braço CON no mesmo momento.

Não foram verificas correlações entre as taxas de cisalhamento durante 0 exercício e o $\triangle \mathrm{FMD}$ nos minutos 15 e 60 , no entanto existiu uma correlação inversa 
significativa entre o índice de oscilação do fluxo e o $\Delta F M D$ no minuto $15(r=-0,49$; $P$ $=0,05)$, demonstrada na Figura 12 .

FIGURA 12 - Correlação entre índice de oscilação do fluxo e $\Delta$ FMD no minuto 15.

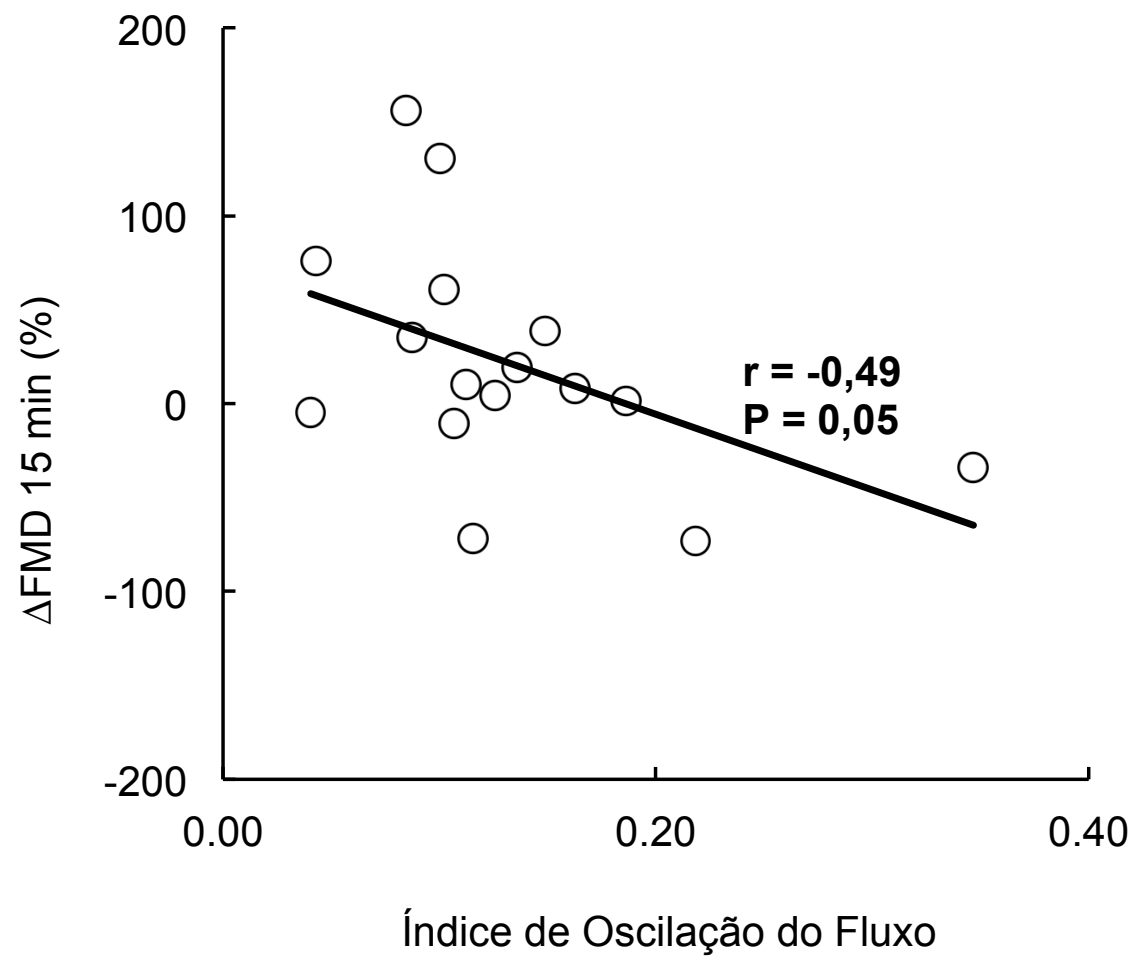




\section{DISCUSSÃO}

O presente estudo examinou os efeitos sub-agudos do exercício de preensão manual combinado com a BFR na função endotelial de homens jovens saudáveis. Os principais achados do estudo foram: 1) FMD estava aumentada no braço CON 15 minutos após uma única sessão de exercício de preensão manual, retornando a valores próximos aos inicias no após 60 minutos; 2) A adição da BFR no braço EXP inibiu o aumento na FMD após o término do exercício; 3) BFR no braço EXP reduziu a taxa de cisalhamento média e aumentou a taxa de cisalhamento retrógrada em repouso e durante a realização do exercício. Desse modo nós estabelecemos que a BFR é prejudicial a resposta sub-aguda da FMD observada após uma sessão de exercício de preensão manual, esse resultado pode ser explicado pelas alterações no padrão do fluxo sanguíneo e taxas de cisalhamento.

Aumentos crônicos na função endotelial em resposta ao treinamento foram reportados de maneira extensiva em diferentes populações (Allen et al., 2003; Beck et al., 2013; Dobrosielski et al., 2009), no entanto foi demonstrado que a adição da BFR ao membro ativo era capaz de inibir essas adaptações benéficas (Tinken et al., 2010). Um estudo recente conduzido por Credeur et al. (2010) reportou uma redução de $30 \%$ na FMD da artéria braquial após 4 semanas de treinamento de preensão manual combinado com BFR, enquanto o braço contralateral que não utilizou o manguito apresentou uma melhora de $25 \%$. Resultados similares podem ser observados em estudos agudos. Aumentos nos valores de FMD após uma única sessão de exercício foram previamente reportados (Harris et al., 2008; Johnson et al., 2012; Tinken et al., 2009; Tinken et al., 2010), ao passo que a adição da BFR 
pode atenuar esta resposta (Tinken et al., 2010) ou levar a uma redução significativa nos valores de FMD (Tinken et al., 2009). O presente estudo encontrou um aumento significativo na FMD após a sessão de exercício somente para o braço CON, enquanto o braço EXP não diferiu significativamente dos valores iniciais em todos os momentos de mensuração, esses achados corroboram os estudos presentes na literatura que avaliaram a resposta aguda da FMD ao exercício. No entanto, não foi observada redução nos valores de FMD do braço EXP em nenhum momento, possivelmente devido a diferenças no protocolo de exercício empregado ou na população estudada (Atkinson et al., 2015; Johnson et al., 2012).

O objetivo principal do presente estudo foi examinar os efeitos sub-agudos de uma única sessão de exercício na função endotelial e no padrão de fluxo sanguíneo. Johnson et al. (2012) reportaram aumento na FMD da artéria braquial imediatamente após uma sessão de exercício sub-máximo na esteira, com os valores retornaram aos iniciais após 1 hora. Similarmente, os maiores valores de FMD observado para o braço CON após o exercício só foram significativos no momento 15 minutos, sem apresentar diferença significativa no minuto 60, Por outro lado Atkinson et al. (2015) não encontraram alteração na FMD da artéria braquial imediatamente um protocolo de preensão manual de baixa intensidade (5, 10 e 15\% da MVC) mas os valores foram significativamente maiores 60 minutos após o término do exercício para a intensidade de $15 \%$ da MVC. Os autores deste último estudo concluíram que a resposta sub-aguda ao exercício de preensão manual pode ser dependente da intensidade, sendo assim as diferenças entre os resultados observados podem ser atribuídas a maior intensidade de exercício utilizada no presente estudo $(60 \%$ da MVC). 
Em relação as alteração sub-agudas no fluxo sanguíneo, não foi observado no presente estudo um aumento significativo no fluxo da artéria braquial após o exercício para ambos os braços em qualquer momento de avaliação. Este resultado vai de encontro aos reportados na literatura. O aumento significativo do fluxo foi previamente demonstrado após uma única sessão de exercício (Baynard et al., 2003; Bousquet-Santos et al., 2005), entretanto estes estudos utilizaram protocolos máximos na esteira, levantando novamente a possibilidade das diferenças observadas serem atribuídas a diferenças nos protocolos de exercício. A AUC $\mathrm{SR}_{\mathrm{S}}$ estava aumentada para os braços CON e EXP 15 minutos após o exercício, retornando a valores inicias após 60 minutos, este resultado está de acordo com um estudo publicado recentemente que empregou um protocolo de exercício similar com menor intensidade (Atkinson et al., 2015). No entanto existem estudos conflitantes na literatura que não reportaram diferenças significativas no $A \cup C_{S R}$ após uma única sessão de exercício (Harris et al., 2008; Tinken et al., 2009). Apesar do AUC $\mathrm{SR}_{\mathrm{S}}$ uma medida do estímulo para a vasodilatação, estar aumentada em ambos os braços após o exercício, somente o braço CON demonstrou um aumento significativo na FMD, sendo assim o maior estímulo de cisalhamento observado durante a hiperemia reativa não é capaz de explicar completamente as alterações na função endotelial reportadas no presente estudo.

Estudos recentes sugerem que modulações no padrão de fluxo sanguíneo e taxas de cisalhamento podem ser responsáveis pelas alterações agudas e crônicas observadas na função endotelial em função do exercício (Credeur et al., 2010; Naylor et al., 2011; Padilla et al., 2011b; Tinken et al., 2009; Tinken et al., 2010). A insuflação de um manguito pneumático durante o exercício altera significativamente 
o padrão de fluxo sanguíneo, atenuando ou inibindo os aumentos nas taxas de cisalhamento média e anterógrada observadas no início do exercício, consequentemente afetando as respostas agudas e crônicas (Tinken et al., 2009; Tinken et al., 2010). Estes dois componentes do fluxo sanguíneo representam um importante estímulo fisiológicos para o endotélio vascular, sendo associados a adaptações benéficas na função endotelial até na ausência do estímulo do exercício (Naylor et al., 2011; Tuttle et al., 2001). Também foi proposto recentemente que as adaptações na função endotelial ocorrem em resposta ao efeito acumulado de episódios de taxa de cisalhamento anterógrada aumentada (Padilla et al., 2011a). Contrário aos estudos prévios a BFR utilizada no presente estudo não reduziu a taxa de cisalhamento anterógrada no braço EXP quando comparado com o braço CON apesar da pressão no manguito $(80 \mathrm{mmHg})$ estar de acordo com a literatura.

Apesar da taxa de cisalhamento anterógrada não ser afetada pela BFR, a taxa de cisalhamento média estava significativamente menor no braço EXP quando comparada com o braço $\mathrm{CON}$, este resultado é atribuído ao aumento da taxa de cisalhamento retrógrado no braço EXP tanto em repouso quando durante a realização do exercício. O aumento do componente retrógrado em resposta a insuflação do manguito foi previamente demonstrado na literatura (Credeur et al., 2010), com estudos recentes demonstrando uma relação dose-resposta significativa entre a pressão no manguito e a magnitude de aumento na taxa de cisalhamento retrógrada (Schreuder et al., 2014, 2015; Thijssen et al., 2009). O aumento no fluxo retrógrado em decorrência da oclusão reportados nestes dois estudos foi correlacionado inversamente com a resposta aguda da FMD, entretanto no presente 
estudo não foram verificadas correlações entre os padrões de fluxo durante o exercício e o $\triangle \mathrm{FMD}$ nos minutos 15 e 60 


\section{CONCLUSÕES}

Uma única sessão de exercício de preensão manual provocou uma melhora sub-aguda na função endotelial 15 minutos após o término do exercício, retornando a valores próximos aos inicias após 60 minutos. A adição de um manguito pneumático insuflado a $80 \mathrm{mmHg}$ no braço experimental inibiu esta resposta aguda. Estes resultados são possivelmente explicados pelas alterações no padrão de fluxo sanguíneo observadas durante o exercício com restrição do fluxo sanguíneo, especialmente o aumento na taxa de cisalhamento retrógrada, aumento do índice de oscilação do fluxo e redução na taxa de cisalhamento média. 


\section{REFERÊNCIAS BIBLIOGRÁFICAS}

AIRD, W. C. Phenotypic heterogeneity of the endothelium: I. Structure, function, and mechanisms. Circulation Research, v. 100, n. 2, p. 158-173, 2007.

AIZAWA, K.; SHOEMAKER, J. K.; OVEREND, T. J.; PETRELLA, R. J. Metabolic syndrome, endothelial function and lifestyle modification. Diabetes \& Vascular Disease Research, v. 6, n. 3, p. 181-189, 2009.

ALLEN, J. D.; GEAGHAN, J. P.; GREENWAY, F.; WELSCH, M. A. Time course of improved flow-mediated dilation after short-term exercise training. Medicine and Science in Sports and Exercise, v. 35, n. 5, p. 847-853, 2003.

ANDERSON, T. J.; UEHATA, A.; GERHARD, M. D.; MEREDITH, I. T.; KNAB, S.; DELAGRANGE, D.; LIEBERMAN, E. H.; GANZ, P.; CREAGER, M. A.; YEUNG, A. C.; ET AL. Close relation of endothelial function in the human coronary and peripheral circulations. Journal of the American College of Cardiology, v. 26, n. 5, p. 1235-1241, 1995.

ATKINSON, C. L.; CARTER, H. H.; DAWSON, E. A.; NAYLOR, L. H.; THIJSSEN, D. H.; GREEN, D. J. Impact of handgrip exercise intensity on brachial artery flowmediated dilation. European Journal of Applied Physiology, v. n. p. 2015.

AYAJIKI, K.; KINDERMANN, M.; HECKER, M.; FLEMING, I.; BUSSE, R. Intracellular ph and tyrosine phosphorylation but not calcium determine shear stress-induced nitric oxide production in native endothelial cells. Circulation Research, v. 78, n. 5, p. 750758, 1996.

BAYNARD, T.; MILLER, W. C.; FERNHALL, B. Effects of exercise on vasodilatory capacity in endurance- and resistance-trained men. European Journal of Applied Physiology, v. 89, n. 1, p. 69-73, 2003. 
BECK, D. T.; CASEY, D. P.; MARTIN, J. S.; EMERSON, B. D.; BRAITH, R. W. Exercise training improves endothelial function in young prehypertensives. Experimental Biology and Medicine (Maywood, N.J.), v. 238, n. 4, p. 433-441, 2013.

BELLIEN, J.; IACOB, M.; GUTIERREZ, L.; ISABELLE, M.; LAHARY, A.; THUILLEZ, C.; JOANNIDES, R. Crucial role of no and endothelium-derived hyperpolarizing factor in human sustained conduit artery flow-mediated dilatation. Hypertension, v. 48, n. 6 , p. 1088-1094, 2006.

BLACK, M. A.; CABLE, N. T.; THIJSSEN, D. H.; GREEN, D. J. Importance of measuring the time course of flow-mediated dilatation in humans. Hypertension, v. 51, n. 2, p. 203-210, 2008.

BOUSQUET-SANTOS, K.; SOARES, P. P.; NOBREGA, A. C. Subacute effects of a maximal exercise bout on endothelium-mediated vasodilation in healthy subjects. Brazilian Journal of Medical and Biological Research, v. 38, n. 4, p. 621-627, 2005.

BREDT, D. S. Endogenous nitric oxide synthesis: Biological functions and pathophysiology. Free Radical Research, v. 31, n. 6, p. 577-596, 1999.

BREVETTI, G.; SILVESTRO, A.; SCHIANO, V.; CHIARIELLO, M. Endothelial dysfunction and cardiovascular risk prediction in peripheral arterial disease: Additive value of flow-mediated dilation to ankle-brachial pressure index. Circulation, v. 108, n. 17, p. 2093-2098, 2003.

BUSSE, R.; MULSCH, A. Calcium-dependent nitric oxide synthesis in endothelial cytosol is mediated by calmodulin. FEBS Letters, v. 265, n. 1-2, p. 133-136, 1990.

BUTT, E.; BERNHARDT, M.; SMOLENSKI, A.; KOTSONIS, P.; FROHLICH, L. G.; SICKMANN, A.; MEYER, H. E.; LOHMANN, S. M.; SCHMIDT, H. H. Endothelial nitric-oxide synthase (type iii) is activated and becomes calcium independent upon 
phosphorylation by cyclic nucleotide-dependent protein kinases. Journal of Biological Chemistry, v. 275, n. 7, p. 5179-5187, 2000.

CAI, H.; HARRISON, D. G. Endothelial dysfunction in cardiovascular diseases: The role of oxidant stress. Circulation Research, v. 87, n. 10, p. 840-844, 2000.

CELERMAJER, D. S.; SORENSEN, K. E.; GOOCH, V. M.; SPIEGELHALTER, D. J.; MILLER, O. I.; SULLIVAN, I. D.; LLOYD, J. K.; DEANFIELD, J. E. Non-invasive detection of endothelial dysfunction in children and adults at risk of atherosclerosis. Lancet, v. 340, n. 8828, p. 1111-1115, 1992.

CHIEN, S. Mechanotransduction and endothelial cell homeostasis: The wisdom of the cell. American Journal of Physiology: Heart and Circulatory Physiology, v. 292, n. 3, p. H1209-1224, 2007.

CLARK, A. M.; HARTLING, L.; VANDERMEER, B.; MCALISTER, F. A. Metaanalysis: Secondary prevention programs for patients with coronary artery disease. Annals of Internal Medicine, v. 143, n. 9, p. 659-672, 2005.

CORRETTI, M. C.; ANDERSON, T. J.; BENJAMIN, E. J.; CELERMAJER, D.; CHARBONNEAU, F.; CREAGER, M. A.; DEANFIELD, J.; DREXLER, H.; GERHARDHERMAN, M.; HERRINGTON, D.; VALLANCE, P.; VITA, J.; VOGEL, R.; INTERNATIONAL BRACHIAL ARTERY REACTIVITY TASK, F. Guidelines for the ultrasound assessment of endothelial-dependent flow-mediated vasodilation of the brachial artery: A report of the international brachial artery reactivity task force. Journal of the American College of Cardiology, v. 39, n. 2, p. 257-265, 2002.

CRECELIUS, A. R.; RICHARDS, J. C.; LUCKASEN, G. J.; LARSON, D. G.; DINENNO, F. A. Reactive hyperemia occurs via activation of inwardly rectifying potassium channels and na+/k+-atpase in humans. Circulation Research, v. 113, n. 8, p. 1023-1032, 2013. 
CREDEUR, D. P.; DOBROSIELSKI, D. A.; ARCE-ESQUIVEL, A. A.; WELSCH, M. A. Brachial artery retrograde flow increases with age: Relationship to physical function. European Journal of Applied Physiology, v. 107, n. 2, p. 219-225, 2009.

CREDEUR, D. P.; HOLLIS, B. C.; WELSCH, M. A. Effects of handgrip training with venous restriction on brachial artery vasodilation. Medicine and Science in Sports and Exercise, v. 42, n. 7, p. 1296-1302, 2010.

DA NOBREGA, A. C. The subacute effects of exercise: Concept, characteristics, and clinical implications. Exercise and Sport Sciences Reviews, v. 33, n. 2, p. 84-87, 2005.

DAWSON, E. A.; WHYTE, G. P.; BLACK, M. A.; JONES, H.; HOPKINS, N.; OXBOROUGH, D.; GAZE, D.; SHAVE, R. E.; WILSON, M.; GEORGE, K. P.; GREEN, D. J. Changes in vascular and cardiac function after prolonged strenuous exercise in humans. J Appl Physiol (1985), v. 105, n. 5, p. 1562-1568, 2008.

DOBROSIELSKI, D. A.; GREENWAY, F. L.; WELSH, D. A.; JAZWINSKI, S. M.; WELSCH, M. A.; LOUISIANA HEALTHY AGING, S. Modification of vascular function after handgrip exercise training in 73- to 90-yr-old men. Medicine and Science in Sports and Exercise, v. 41, n. 7, p. 1429-1435, 2009.

DONNELLY, R.; HINWOOD, D.; LONDON, N. J. Abc of arterial and venous disease. Non-invasive methods of arterial and venous assessment. BMJ, v. 320, n. 7236, p. 698-701, 2000.

DOSHI, S. N.; NAKA, K. K.; PAYNE, N.; JONES, C. J.; ASHTON, M.; LEWIS, M. J.; GOODFELLOW, J. Flow-mediated dilatation following wrist and upper arm occlusion in humans: The contribution of nitric oxide. Clinical Science (London, England: 1979), v. 101, n. 6, p. 629-635, 2001. 
ENDEMANN, D. H.; SCHIFFRIN, E. L. Endothelial dysfunction. Journal of the American Society of Nephrology, v. 15, n. 8, p. 1983-1992, 2004.

FERNANDES, I. A.; SALES, A. R.; ROCHA, N. G.; SILVA, B. M.; VIANNA, L. C.; DA NOBREGA, A. C. Preserved flow-mediated dilation but delayed time-to-peak diameter in individuals with metabolic syndrome. Clinical Physiology and Functional Imaging, v. 34, n. 4, p. 270-276, 2014.

FORSTERMANN, U.; SCHMIDT, H. H.; POLLOCK, J. S.; SHENG, H.; MITCHELL, J. A.; WARNER, T. D.; NAKANE, M.; MURAD, F. Isoforms of nitric oxide synthase. Characterization and purification from different cell types. Biochemical Pharmacology, v. 42 , n. 10 , p. 1849-1857, 1991.

FRY, C. S.; GLYNN, E. L.; DRUMMOND, M. J.; TIMMERMAN, K. L.; FUJITA, S.; ABE, T.; DHANANI, S.; VOLPI, E.; RASMUSSEN, B. B. Blood flow restriction exercise stimulates mtorc1 signaling and muscle protein synthesis in older men. $J$ Appl Physiol (1985), v. 108, n. 5, p. 1199-1209, 2010.

FURCHGOTT, R. F.; ZAWADZKI, J. V. The obligatory role of endothelial cells in the relaxation of arterial smooth muscle by acetylcholine. Nature, v. 288, n. 5789 , p. 373376, 1980.

GAUTAM, M.; GOJOVA, A.; BARAKAT, A. I. Flow-activated ion channels in vascular endothelium. Cell Biochemistry and Biophysics, v. 46, n. 3, p. 277-284, 2006.

GHIADONI, L.; FAITA, F.; SALVETTI, M.; CORDIANO, C.; BIGGI, A.; PUATO, M.; DI MONACO, A.; DE SIATI, L.; VOLPE, M.; AMBROSIO, G.; GEMIGNANI, V.; MUIESAN, M. L.; TADDEI, S.; LANZA, G. A.; COSENTINO, F. Assessment of flowmediated dilation reproducibility: $A$ nationwide multicenter study. Journal of Hypertension, v. 30, n. 7, p. 1399-1405, 2012. 
GREEN, D. J.; O'DRISCOLL, G.; JOYNER, M. J.; CABLE, N. T. Exercise and cardiovascular risk reduction: Time to update the rationale for exercise? J Appl Physiol (1985), v. 105, n. 2, p. 766-768, 2008.

HAMBRECHT, R.; WALTHER, C.; MOBIUS-WINKLER, S.; GIELEN, S.; LINKE, A.; CONRADI, K.; ERBS, S.; KLUGE, R.; KENDZIORRA, K.; SABRI, O.; SICK, P.; SCHULER, G. Percutaneous coronary angioplasty compared with exercise training in patients with stable coronary artery disease: A randomized trial. Circulation, v. 109, n. 11 , p. 1371-1378, 2004.

HAMER, M.; INGLE, L.; CARROLL, S.; STAMATAKIS, E. Physical activity and cardiovascular mortality risk: Possible protective mechanisms? Medicine and Science in Sports and Exercise, v. 44, n. 1, p. 84-88, 2012.

HARRIS, R. A.; NISHIYAMA, S. K.; WRAY, D. W.; RICHARDSON, R. S. Ultrasound assessment of flow-mediated dilation. Hypertension, v. 55, n. 5, p. 1075-1085, 2010.

HARRIS, R. A.; PADILLA, J.; HANLON, K. P.; RINK, L. D.; WALLACE, J. P. The flowmediated dilation response to acute exercise in overweight active and inactive men. Obesity (Silver Spring), v. 16, n. 3, p. 578-584, 2008.

HARVEY, P. J.; MORRIS, B. L.; KUBO, T.; PICTON, P. E.; SU, W. S.; NOTARIUS, C. F.; FLORAS, J. S. Hemodynamic after-effects of acute dynamic exercise in sedentary normotensive postmenopausal women. Journal of Hypertension, v. 23, n. 2, p. 285$292,2005$.

HENRY, R. M.; FERREIRA, I.; KOSTENSE, P. J.; DEKKER, J. M.; NIJPELS, G.; HEINE, R. J.; KAMP, O.; BOUTER, L. M.; STEHOUWER, C. D. Type 2 diabetes is associated with impaired endothelium-dependent, flow-mediated dilation, but impaired glucose metabolism is not; the hoorn study. Atherosclerosis, v. 174, n. 1, p. 49-56, 2004. 
HUNT, J. E.; WALTON, L. A.; FERGUSON, R. A. Brachial artery modifications to blood flow-restricted handgrip training and detraining. J Appl Physiol (1985), v. 112, n. 6, p. 956-961, 2012.

IGNARRO, L. J.; BUGA, G. M.; WOOD, K. S.; BYRNS, R. E.; CHAUDHURI, G. Endothelium-derived relaxing factor produced and released from artery and vein is nitric oxide. Proceedings of the National Academy of Sciences of the United States of America, v. 84, n. 24, p. 9265-9269, 1987.

INABA, Y.; CHEN, J. A.; BERGMANN, S. R. Prediction of future cardiovascular outcomes by flow-mediated vasodilatation of brachial artery: A meta-analysis. International Journal of Cardiovascular Imaging, v. 26, n. 6, p. 631-640, 2010.

JOHNSON, B. D.; PADILLA, J.; WALLACE, J. P. The exercise dose affects oxidative stress and brachial artery flow-mediated dilation in trained men. European Journal of Applied Physiology, v. 112, n. 1, p. 33-42, 2012.

JONES, H.; GREEN, D. J.; GEORGE, K.; ATKINSON, G. Intermittent exercise abolishes the diurnal variation in endothelial-dependent flow-mediated dilation in humans. American Journal of Physiology: Regulatory, Integrative and Comparative Physiology, v. 298, n. 2, p. R427-432, 2010.

KANG, K. T. Endothelium-derived relaxing factors of small resistance arteries in hypertension. Toxicol Res, v. 30, n. 3, p. 141-148, 2014.

KEMP-HARPER, B.; SCHMIDT, H. H. Cgmp in the vasculature. Handbook of Experimental Pharmacology, v. n. 191, p. 447-467, 2009.

KING, T. J.; SLATTERY, D. J.; PYKE, K. E. The impact of handgrip exercise duty cycle on brachial artery flow-mediated dilation. European Journal of Applied Physiology, v. 113, n. 7, p. 1849-1858, 2013. 
KOEPPEN, M.; FEIL, R.; SIEGL, D.; FEIL, S.; HOFMANN, F.; POHL, U.; DE WIT, C. Cgmp-dependent protein kinase mediates no- but not acetylcholine-induced dilations in resistance vessels in vivo. Hypertension, v. 44, n. 6, p. 952-955, 2004.

LANGILLE, B. L.; O'DONNELL, F. Reductions in arterial diameter produced by chronic decreases in blood flow are endothelium-dependent. Science, v. 231, n. 4736, p. 405-407, 1986.

LAUGHLIN, M. H.; NEWCOMER, S. C.; BENDER, S. B. Importance of hemodynamic forces as signals for exercise-induced changes in endothelial cell phenotype. J Appl Physiol (1985), v. 104, n. 3, p. 588-600, 2008.

LERMAN, A.; ZEIHER, A. M. Endothelial function: Cardiac events. Circulation, v. 111, n. 3, p. 363-368, 2005.

LUKSHA, L.; AGEWALL, S.; KUBLICKIENE, K. Endothelium-derived hyperpolarizing factor in vascular physiology and cardiovascular disease. Atherosclerosis, v. 202, n. 2, p. 330-344, 2009.

MARKWALD, R. R.; KIRBY, B. S.; CRECELIUS, A. R.; CARLSON, R. E.; VOYLES, W. F.; DINENNO, F. A. Combined inhibition of nitric oxide and vasodilating prostaglandins abolishes forearm vasodilatation to systemic hypoxia in healthy humans. Journal of Physiology, v. 589, n. Pt 8, p. 1979-1990, 2011.

MORA, S.; COOK, N.; BURING, J. E.; RIDKER, P. M.; LEE, I. M. Physical activity and reduced risk of cardiovascular events: Potential mediating mechanisms. Circulation, v. 116, n. 19, p. 2110-2118, 2007.

MULLEN, M. J.; KHARBANDA, R. K.; CROSS, J.; DONALD, A. E.; TAYLOR, M.; VALLANCE, P.; DEANFIELD, J. E.; MACALLISTER, R. J. Heterogenous nature of flow-mediated dilatation in human conduit arteries in vivo : Relevance to endothelial 
dysfunction in hypercholesterolemia. Circulation Research, v. 88, n. 2, p. 145-151, 2001.

NAYLOR, L. H.; CARTER, H.; FITZSIMONS, M. G.; CABLE, N. T.; THIJSSEN, D. H.; GREEN, D. J. Repeated increases in blood flow, independent of exercise, enhance conduit artery vasodilator function in humans. American Journal of Physiology: Heart and Circulatory Physiology, v. 300, n. 2, p. H664-669, 2011.

NAYLOR, L. H.; WEISBROD, C. J.; O'DRISCOLL, G.; GREEN, D. J. Measuring peripheral resistance and conduit arterial structure in humans using doppler ultrasound. J Appl Physiol (1985), v. 98, n. 6, p. 2311-2315, 2005.

PADILLA, J.; JOHNSON, B. D.; NEWCOMER, S. C.; WILHITE, D. P.; MICKLEBOROUGH, T. D.; FLY, A. D.; MATHER, K. J.; WALLACE, J. P. Adjusting flow-mediated dilation for shear stress stimulus allows demonstration of endothelial dysfunction in a population with moderate cardiovascular risk. Journal of Vascular Research, v. 46, n. 6, p. 592-600, 2009.

PADILLA, J.; SIMMONS, G. H.; BENDER, S. B.; ARCE-ESQUIVEL, A. A.; WHYTE, J. J.; LAUGHLIN, M. H. Vascular effects of exercise: Endothelial adaptations beyond active muscle beds. Physiology (Bethesda), v. 26, n. 3, p. 132-145, 2011a.

PADILLA, J.; SIMMONS, G. H.; VIANNA, L. C.; DAVIS, M. J.; LAUGHLIN, M. H.; FADEL, P. J. Brachial artery vasodilatation during prolonged lower limb exercise: Role of shear rate. Experimental Physiology, v. 96, n. 10, p. 1019-1027, 2011b.

PALMER, R. M.; ASHTON, D. S.; MONCADA, S. Vascular endothelial cells synthesize nitric oxide from l-arginine. Nature, v. 333, n. 6174, p. 664-666, 1988.

PALMER, R. M.; FERRIGE, A. G.; MONCADA, S. Nitric oxide release accounts for the biological activity of endothelium-derived relaxing factor. Nature, v. 327, n. 6122, p. 524-526, 1987. 
PANZA, J. A.; QUYYUMI, A. A.; BRUSH, J. E., Jr.; EPSTEIN, S. E. Abnormal endothelium-dependent vascular relaxation in patients with essential hypertension. New England Journal of Medicine, v. 323, n. 1, p. 22-27, 1990.

PARK, J. B.; CHARBONNEAU, F.; SCHIFFRIN, E. L. Correlation of endothelial function in large and small arteries in human essential hypertension. Journal of Hypertension, v. 19, n. 3, p. 415-420, 2001.

PARK, J. B.; SCHIFFRIN, E. L. Small artery remodeling is the most prevalent (earliest?) form of target organ damage in mild essential hypertension. Journal of Hypertension, v. 19, n. 5, p. 921-930, 2001.

PARKER, B. A.; TSCHAKOVSKY, M. E.; AUGERI, A. L.; POLK, D. M.; THOMPSON, P. D.; KIERNAN, F. J. Heterogenous vasodilator pathways underlie flow-mediated dilation in men and women. American Journal of Physiology: Heart and Circulatory Physiology, v. 301, n. 3, p. H1118-1126, 2011.

PASYK, K. A.; JAKOBCZAK, B. A. Vascular endothelium: Recent advances. European Journal of Dermatology, v. 14, n. 4, p. 209-213, 2004.

PENNATI, G.; BELLOTTI, M.; FERRAZZI, E.; BOZZO, M.; PARDI, G.; FUMERO, R. Blood flow through the ductus venosus in human fetus: Calculation using doppler velocimetry and computational findings. Ultrasound in Medicine and Biology, v. 24, n. 4, p. 477-487, 1998.

PICON, R. V.; FUCHS, F. D.; MOREIRA, L. B.; RIEGEL, G.; FUCHS, S. C. Trends in prevalence of hypertension in brazil: A systematic review with meta-analysis. PloS One, v. 7, n. 10, p. e48255, 2012. 
POHL, U.; HOLTZ, J.; BUSSE, R.; BASSENGE, E. Crucial role of endothelium in the vasodilator response to increased flow in vivo. Hypertension, v. 8, n. 1, p. 37-44, 1986.

PYKE, K.; GREEN, D. J.; WEISBROD, C.; BEST, M.; DEMBO, L.; O'DRISCOLL, G.; TSCHAKOVSKY, M. Nitric oxide is not obligatory for radial artery flow-mediated dilation following release of 5 or $10 \mathrm{~min}$ distal occlusion. American Journal of Physiology: Heart and Circulatory Physiology, v. 298, n. 1, p. H119-126, 2010.

PYKE, K. E.; TSCHAKOVSKY, M. E. The relationship between shear stress and flowmediated dilatation: Implications for the assessment of endothelial function. Journal of Physiology, v. 568, n. Pt 2, p. 357-369, 2005.

RIZZONI, D.; PORTERI, E.; GUELFI, D.; MUIESAN, M. L.; VALENTINI, U.; CIMINO, A.; GIRELLI, A.; RODELLA, L.; BIANCHI, R.; SLEIMAN, I.; ROSEI, E. A. Structural alterations in subcutaneous small arteries of normotensive and hypertensive patients with non-insulin-dependent diabetes mellitus. Circulation, v. 103, n. 9, p. 1238-1244, 2001.

RUBANYI, G. M.; ROMERO, J. C.; VANHOUTTE, P. M. Flow-induced release of endothelium-derived relaxing factor. American Journal of Physiology, v. 250, n. $6 \mathrm{Pt}$ 2, p. H1145-1149, 1986.

SCHOFIELD, I.; MALIK, R.; IZZARD, A.; AUSTIN, C.; HEAGERTY, A. Vascular structural and functional changes in type 2 diabetes mellitus: Evidence for the roles of abnormal myogenic responsiveness and dyslipidemia. Circulation, v. 106, n. 24, p. 3037-3043, 2002.

SCHREUDER, T. H.; GREEN, D. J.; HOPMAN, M. T.; THIJSSEN, D. H. Acute impact of retrograde shear rate on brachial and superficial femoral artery flow-mediated dilation in humans. Physiol Rep, v. 2, n. 1, p. e00193, 2014. 
SCHREUDER, T. H.; GREEN, D. J.; HOPMAN, M. T.; THIJSSEN, D. H. Impact of retrograde shear rate on brachial and superficial femoral artery flow-mediated dilation in older subjects. Atherosclerosis, v. n. p. 2015.

SESSO, H. D.; PAFFENBARGER, R. S., Jr.; LEE, I. M. Physical activity and coronary heart disease in men: The harvard alumni health study. Circulation, v. 102, n. 9, p. 975-980, 2000.

STUEHR, D. J. Structure-function aspects in the nitric oxide synthases. Annual Review of Pharmacology and Toxicology, v. 37, n. p. 339-359, 1997.

SUWAIDI, J. A.; HAMASAKI, S.; HIGANO, S. T.; NISHIMURA, R. A.; HOLMES, D. R., Jr.; LERMAN, A. Long-term follow-up of patients with mild coronary artery disease and endothelial dysfunction. Circulation, v. 101, n. 9, p. 948-954, 2000.

SUZUKI, T.; HIRATA, K.; ELKIND, M. S.; JIN, Z.; RUNDEK, T.; MIYAKE, Y.; BODENALBALA, B.; DI TULLIO, M. R.; SACCO, R.; HOMMA, S. Metabolic syndrome, endothelial dysfunction, and risk of cardiovascular events: The northern manhattan study (nomas). American Heart Journal, v. 156, n. 2, p. 405-410, 2008.

TAKARADA, Y.; TAKAZAWA, H.; SATO, Y.; TAKEBAYASHI, S.; TANAKA, Y.; ISHII, $\mathrm{N}$. Effects of resistance exercise combined with moderate vascular occlusion on muscular function in humans. J Appl Physiol (1985), v. 88, n. 6, p. 2097-2106, 2000.

THIJSSEN, D. H.; DAWSON, E. A.; TINKEN, T. M.; CABLE, N. T.; GREEN, D. J. Retrograde flow and shear rate acutely impair endothelial function in humans. Hypertension, v. 53, n. 6, p. 986-992, 2009.

THIJSSEN, D. H.; MAIORANA, A. J.; O'DRISCOLL, G.; CABLE, N. T.; HOPMAN, M. T.; GREEN, D. J. Impact of inactivity and exercise on the vasculature in humans. European Journal of Applied Physiology, v. 108, n. 5, p. 845-875, 2010. 
TINKEN, T. M.; THIJSSEN, D. H.; HOPKINS, N.; BLACK, M. A.; DAWSON, E. A.; MINSON, C. T.; NEWCOMER, S. C.; LAUGHLIN, M. H.; CABLE, N. T.; GREEN, D. J. Impact of shear rate modulation on vascular function in humans. Hypertension, v. 54, n. 2, p. 278-285, 2009.

TINKEN, T. M.; THIJSSEN, D. H.; HOPKINS, N.; DAWSON, E. A.; CABLE, N. T.; GREEN, D. J. Shear stress mediates endothelial adaptations to exercise training in humans. Hypertension, v. 55, n. 2, p. 312-318, 2010.

TOUSOULIS, D.; ANTONIADES, C.; STEFANADIS, C. Evaluating endothelial function in humans: A guide to invasive and non-invasive techniques. Heart, v. 91, n. 4, p. 553-558, 2005.

TOUSOULIS, D.; KAMPOLI, A. M.; TENTOLOURIS, C.; PAPAGEORGIOU, N.; STEFANADIS, C. The role of nitric oxide on endothelial function. Current Vascular Pharmacology, v. 10, n. 1, p. 4-18, 2012.

TUTTLE, J. L.; NACHREINER, R. D.; BHULLER, A. S.; CONDICT, K. W.; CONNORS, B. A.; HERRING, B. P.; DALSING, M. C.; UNTHANK, J. L. Shear level influences resistance artery remodeling: Wall dimensions, cell density, and enos expression. American Journal of Physiology: Heart and Circulatory Physiology, v. 281, n. 3, p. H1380-1389, 2001.

VIEIRA, P. J.; CHIAPPA, G. R.; UMPIERRE, D.; STEIN, R.; RIBEIRO, J. P. Hemodynamic responses to resistance exercise with restricted blood flow in young and older men. Journal of Strength and Conditioning Research, v. 27, n. 8, p. 22882294, 2013.

WELSCH, M. A.; DOBROSIELSKI, D. A.; ARCE-ESQUIVEL, A. A.; WOOD, R. H.; RAVUSSIN, E.; ROWLEY, C.; JAZWINSKI, S. M. The association between flowmediated dilation and physical function in older men. Medicine and Science in Sports and Exercise, v. 40, n. 7, p. 1237-1243, 2008. 
WIDLANSKY, M. E.; GOKCE, N.; KEANEY, J. F.; VITA, J. A. The clinical implications of endothelial dysfunction. Journal of the American College of Cardiology, v. 42, n. 7, p. 1149-1160, 2003.

WRAY, D. W.; WITMAN, M. A.; IVES, S. J.; MCDANIEL, J.; TRINITY, J. D.; CONKLIN, J. D.; SUPIANO, M. A.; RICHARDSON, R. S. Does brachial artery flowmediated vasodilation provide a bioassay for no? Hypertension, v. 62, n. 2, p. 345351, 2013.

YEBOAH, J.; CROUSE, J. R.; HSU, F. C.; BURKE, G. L.; HERRINGTON, D. M. Brachial flow-mediated dilation predicts incident cardiovascular events in older adults: The cardiovascular health study. Circulation, v. 115, n. 18, p. 2390-2397, 2007.

ZHANG, X.; ZHAO, S. P.; LI, X. P.; GAO, M.; ZHOU, Q. C. Endothelium-dependent and -independent functions are impaired in patients with coronary heart disease. Atherosclerosis, v. 149, n. 1, p. 19-24, 2000. 


\section{LISTA DE ANEXOS}

Página

ANEXO A - TERMO DE CONSENTIMENTO LIVRE E ESCLARECIDO ................. 67

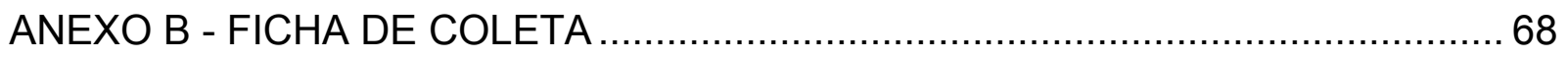




\section{ANEXO A - TERMO DE CONSENTIMENTO LIVRE E ESCLARECIDO}

\section{Universidade de Brasília}

\section{TERMO DE CONSENTIMENTO LIVRE E ESCLARECIDO}

Você está sendo convidado para participar de uma pesquisa que tem como objetivo verificar os efeitos sub-agudos do exercício físico combinado ou não com o método de oclusão vascular na função endotelial de homens jovens. O presente projeto foi submetido ao Comitê de Ética em Pesquisa da Faculdade de Ciências da saúde da Universidade de Brasília de acordo com a Resolução n 196/96 do Conselho Nacional de Saúde (CNS) que regulamenta as pesquisas envolvendo seres humanos.

Serão realizados procedimentos não-invasivos para mensuração da função endotelial (dilatação fluxo-mediada), frequência cardíaca (eletrocardiograma), pressão arterial e força muscular (contração voluntária máxima). Todas as análises serão realizadas no campus da Universidade Federal Fluminense no Laboratório de Ciências do Exercício, sendo necessária somente uma visita ao laboratório com duração aproximada de 2 horas. Antes de comparecer ao laboratório será necessário permanecer de jejum, se abster do consumo de cafeína, tabaco, álcool e não realizar atividades físicas vigorosas por no mínimo 12 horas.

Os resultados desta pesquisa serão utilizados com finalidades de publicação em revistas científicas especializadas e apresentação em congressos nacionais e internacionais, sendo resguardada a identidade dos voluntários em todos os momentos. Os dados e informações obtidas durante a pesquisa ficarão sob a responsabilidade do pesquisador responsável Flávio Macedo Lahud Paiva, o qual poderá ser contatado pelo número (61) 9657-6055 ou pelo e-mail flavio.lahud@gmail.com.

"Li as informações acima, recebi as explicações sobre a pesquisa e desejo participar voluntariamente. Estou ciente de que posso retirar meu consentimento e interromper minha participação a qualquer momento. Uma cópia deste documento me será dada."

Participante Voluntário

Data:
Flávio Macedo Lahud Paiva

Data: 


\section{Universidade de Brasília}

FICHA DE COLETA

Sujeito $\mathrm{N}^{\circ}$ :

Data: 1 I Horário:

Nome:

Data de Nascimento:

Massa Corporal:

kg Estatura: $\mathrm{m}$

Braço Experimental: ( ) Esquerdo ( ) Direito

BRAÇO CONTROLE (CVM: N)

\begin{tabular}{|c|c|c|}
\hline Repouso & 15 minutos & 60 minutos \\
\hline D. Repouso: __ $\mathrm{mm}$ & D. Repouso: _ $\mathrm{mm}$ & D. Repouso: \\
\hline D. Pico: __ & D. Pico: __ $\mathrm{mm}$ & D. Pico: __ $\mathrm{mm}$ \\
\hline FMD: $\quad \%$ & FMD: $\quad \%$ & FMD: \\
\hline
\end{tabular}

BRAÇO EXPERIMENTAL (CVM: N)

\section{Repouso}

D. Repouso:

D. Pico:

FMD: $\mathrm{mm}$ $\%$

Borg 10:

\section{5 minutos}

D. Repouso:

D. Pico:

FMD: $\mathrm{mm}$

$\%$

\section{0 minutos}

D. Repouso:

D. Pico: $\mathrm{mm}$ FMD: $\mathrm{mm}$ $\%$ 